IONIZATION IN SEEDED DETONATION WAVES

by

SATYAKI BASU

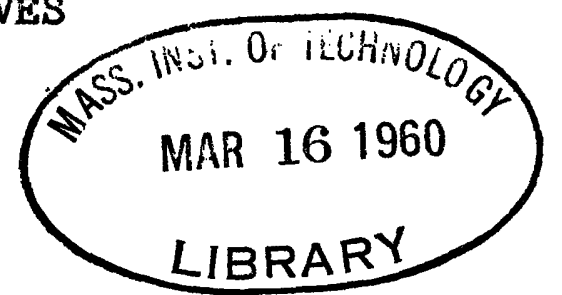

B.E. (Mech) University of Bombay

(1954)

S.M. Massachusetts Institute of Technology

(1955)

SUBMITTED IN PARTIAL FULFILLMENT
OF THE REQUIREMENTS FOR THE

DEGREE OF DOCTOR OF

SCIENCE

at the

MASSACHUSETTS INSTITUTE OF

TECHNOLOGY

September, 1959

Signature of Author Department of Mechanical Engineering, September 28, 1959

Certified by ....

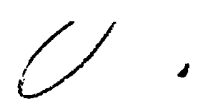

Thesip/Supervisor

Accepted by.$\cdots \cdots \cdots$ - Chairman, Departmental Committè on Graduate Students 


\section{IONIZATION IN SEEDED DETONATION WAVES}

by

Satyaki Basu

Submitted to the Department of Mechanical Engineering on September 30, 1959, in partial fulfillment of the requirements for the degree of Doctor of Science

\section{ABSTRACT}

It has been reported that equilibrium ionization is achieved in about 20 microseconds behind oxy-hydrogen and oxy-acetylene detonation waves (1), and that the electrical conductivity of the gas behind the detonations is of the order of $10^{-3}$ mos $/ \mathrm{cm}$. To obtain magnetohydrodynamic interaction with reasonable magnetic fields, conductivities of the order of $10 \mathrm{mhos} / \mathrm{cm}$ are required of combustion gases. This thesis reports on an investigation of oxy-acetylene detonations at $1 / 10$ atmosphere initial pressure, which were seeded with Potassium Acetylide $\left(\mathrm{C}_{2} \mathrm{HK}\right)$ to obtain the high conductivity mentioned above.

Finely ground Potassium Acetylide was injected into the initial mixture and the concentration of the resulting aerosol was determined by a sedimentation technique. The electrical conductivity was determined by a magnetohydrodynamic interaction method developed by Lin et al (4). The measured conductivities were plotted as a function of the mole per cent of Potassium added and compared with the results of thermodynamic equilibrium calculations. Predicted and measured conductivities have approximately the same dependence on the concentration of Potassium, which was varied from 0.1 per cent to 10 per cent. Absolute values agreed within a factor of two, the agreement improving with increasing mole fraction of Potassium; an extrapolated value of $10^{-15} \mathrm{sq} \mathrm{cm}$ being used for the electron-gas collision cross section in the calculation of the conductivity. There is some uncertainty in this value, and a value twice this gave good agreement between theory and experiment. The maximum measured conductivity was $2.7 \mathrm{mho} / \mathrm{cm}$ and occurred at about 3 mole per cent Potassium in the product gases.

Thesis Supervisor: J. A. Fay

Title: Associate Professor of Mechanical Engineering 
Massachusetts Institute of Technology

Cambridge 39, Massachusetts

September 30,1959

Professor Philip Franklin

Secretary of the Faculty

Massachusetts Institute of Technology

Cambridge 39 , Massachusetts

Dear Sir:

In accordance with the regulations of the faculty, I hereby submit a thesis entitled "Ionization in Seeded Detonation Waves," in partial fulfillment of the requirements for the degree of Doctor of Science in Mechanical Engineering.

Respectfully submitted,

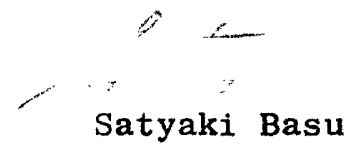


Dedicated to my parents, but for whose forethought, sacrifice and encouragement this work could never have been undertaken. 


\section{ACKNOWLEDGEMENTS}

The author is particularly indebted to Professor J. A. Fay, his thesis supervisor, for his constant guidance and encouragement. He wishes to thank Professor O. K. Mawardi and Professor W. P. Allis, the other members of h1s. Thesis Committee, for helpful suggestions. Dr. J. Tuzson of Whirlpool Corporation advised the author on methods of generating aerosols. He wishes to express his gratitude to his colleagues at the Detonation Laboratory, especially to Mr. William T. Hogan for taking the conductivity data, to Mr. Gerhard L. Opel for his help in the laboratory, to Mr. W. Craig Moffatt for helping with the calculations and to Mr. Luclen Donadieu for the preparation and determination of physical and chemical properties of the Potassium Acetylide powder used in the experiments. Thanks are due to Mr. R. E. Duff of the Los Alamos Sclentific Laboratory for the loan of an IBM 704 Computer Program for the calculation of detonation wave parameters. A major part of the calculations involved in this thesis were performed on the IBM 704 computer at M.I.T.

The work was done under the sponsorship of Project SQUID which is supported by the Office of Naval Research, Department of the Navy, under Contract Nonr1858(25)NR-098-038. 
TABLE OF CONTENTS

page

Title page $\ldots \ldots \ldots \ldots \ldots \ldots \ldots \ldots \ldots \ldots \ldots \ldots \ldots \ldots$

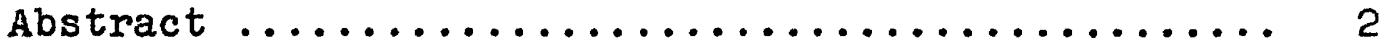

Letter of transmittal $\ldots \ldots \ldots \ldots \ldots \ldots \ldots \ldots \ldots$

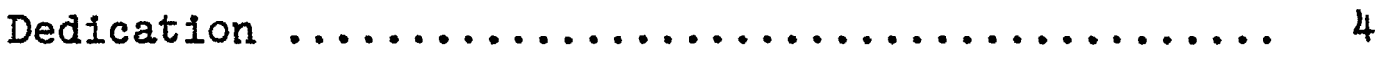

Acknowledgements ...................... 5

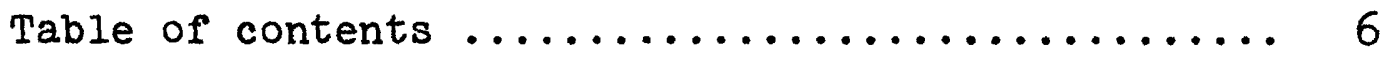

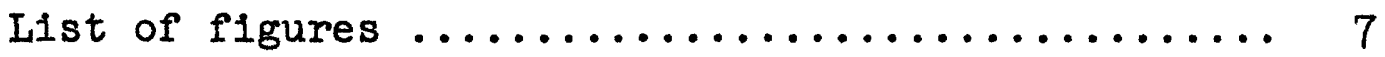

I. Introduction $\ldots \ldots \ldots \ldots \ldots \ldots \ldots \ldots \ldots$

II. Apparatus $\ldots \ldots \ldots \ldots \ldots \ldots \ldots \ldots \ldots \ldots \ldots \ldots \ldots$

III. Theoretical computation of the electrical conductivity ............. 19

IV. Results and Discussion $\ldots \ldots \ldots \ldots \ldots \ldots \ldots 26$

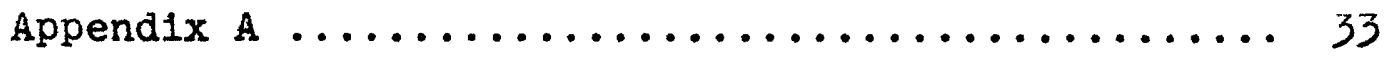

Appendix B .............................. 39

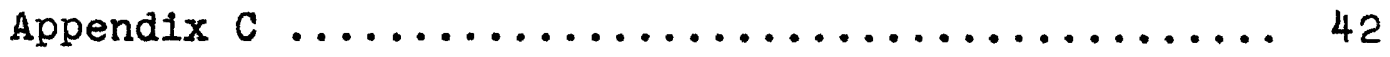

Appendix $D \ldots \ldots \ldots \ldots \ldots \ldots \ldots \ldots \ldots \ldots \ldots \ldots \ldots \ldots$

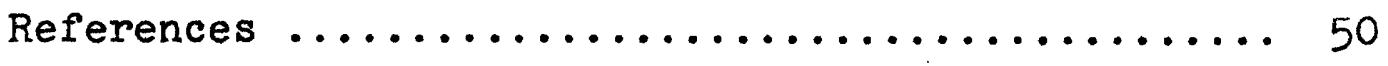

Biographical Note $\ldots \ldots \ldots \ldots \ldots \ldots \ldots \ldots \ldots \ldots, 52$

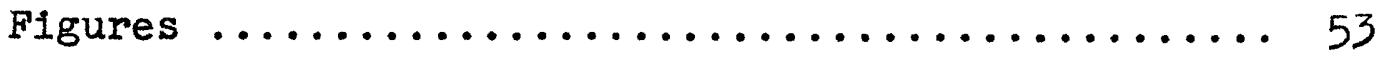




\section{LIST OF FIGURES}

1. Schematic diagram of over-all equipment.

2. Typical experimental curve of accumulated weight of $\mathrm{C}_{2} \mathrm{HK}$ versus time elapsed after injection.

3. Density of powder at test section as a function of time elapsed after injection for different amounts of injected powder.

4. Schematic diagram of search coil used to measure electrical conductivity.

5. Calibration oscillogram obtained with the apparatus by passing an aluminum slug through the detonation tube at $600 \mathrm{~cm} / \mathrm{sec}$.

6. Typical oscillograms obtained with the apparatus when seeded detonation waves passed through the magnetic field.

7. Table showing properties of fictitious gas $X$ used to simulate the presence of the solid additive in the reactants.

8. Tabulation of gas properties behind seeded oxyacetylene detonations.

9. Tabulation of the theoretical conductivity of the gas together with the contribution to it of the different species.

10. Comparison between theoretical and experimental values of electrical conductivity as a function of mole fraction of Potassium. 
11. Diffusion time versus mole fraction of Potassium for 10 micron particles.

12. Theoretical electrical conductivity as a function of mole fraction of Potassium showing effect of pressure and temperature.

13. Tabulation of experimental conductivity data showing estimated temperature rise in the second wave.

14. Comparison between modified theoretical conductivity and experimental values, also showing estimated conductivities obtainable with Cesium. 


\section{INTRODUCTION}

The electrical conductivity of combustion gases is a property which may be of great use in application to rocket propellant systems. If the conductivity is high enough, it may be possible either to generate power from the flow or to accelerate the flow by passing the combustion gases through a crossed electric and magnetic field. The pressures, temperatures, flow velocities, etc., encountered in rocket propellant systems may be obtained in the laboratory by means of gaseous detonation waves. It has been found that thermodynamic equilibrium with respect to ion formation is achieved in oxy-hydrogen and oxy-acetylene detonation waves and that ionization is complete in about 10 microseconds for mixtures at one atmosphere initial pressure, (1). The electrical conductivity of the gas behind these detonations is of the order of $10^{-3} \mathrm{mhos} / \mathrm{cm}$. The conductivity required to obtain magnetohydrodynamic interaction with reasonable magnetic fields may be calculated as follows:

Consider a gas of conductivity $\sigma$ moving with a velocity $\underline{v}$ at right angles to a uniform magnetic field $\underline{B}$. A current $j$ is induced in the gas if a closed path exists for it, and its magnitude and direction are given by $\underline{\mathcal{f}}=\sigma(\underline{v} \times \underline{B})$. This causes a body force $\underline{F}=\underline{j} \times \underline{B}=\sigma(\underline{v} \times \underline{B}) \times \underline{B}$, in a direction opposing the flow. If the field is maintained over a length 1 , then the pressure difference retarding the flow will be 
$\underline{F} I=\sigma I(\underline{v} \times \underline{B}) \times \underline{B}$. To obtain an interaction this pressure difference must be of the order of the pressure of the gas behind the detonation wave. For a detonation at $1 / 10 \mathrm{~atm}$. initial pressure this may be assumed to be about 1.5 atm. Assuming $\mathrm{v}=1.5 \times 10^{5} \mathrm{~cm} / \mathrm{sec}, 1=10 \mathrm{~cm}$, and $\mathrm{B}=10,000$ gauss, we get $\sigma=10 \mathrm{mhos} / \mathrm{cm}$.

Electrical conductivities of the order of 10 mhos $/ \mathrm{cm}$ can be obtained behind detonation waves if about 1 per cent of the gas is ionized. A large fraction of alkali metals like Cesium or Potassium is ionized at the temperatures (3500-4000 degrees Kelvin) obtained behind detonation waves. Hence the introduction of about 1 per cent of such a metal into the gas would produce the desired effect if the temperature of the gas were not appreciably lowered.

Alkali metals have been introduced in flames by spraying alkal1 salt solutions into the reactant gas stream (2). The solution droplets vaporize in the flame, the salt dissociates, and then the metal atoms ionize. This method may not be advantageous with detonations because of the short duration of time available in an experiment - about 100 microseconds as compared to 100 milliseconds in a flame experiment. An alternative method would be to evaporate the alkali metal into a heated reactant gas. The initial temperatures required are not high (500-700 degrees Kelvin) but the reactive nature of the alkali metals introduces numerous practical difficulties which make this method unsuitable. Yet another 
alternative would be to evaporate a liquid salt of Potassium or Cesium in a heated reactant gas. A careful review of the literature, however, failed to reveal a single salt of the above metals which is liquid at temperatures of up to $700^{\circ} \mathrm{K}$., and hence this method was discarded. Finally, it was decided to introduce the alkali metal in the shape of a finely ground powder of a salt uniformly dispersed in the reactant gas.

The cholce of a suitable powder involves two main considerations: 1) It must be easily dispersible in the gas, 1.e., it must be available in finely ground condition, it must have a low density, it must not be hygroscopic, etc. 2) It must have a simple molecular structure with low dissociation energy.

The compound which best satisfied these requirements was found to be a rare compound known as the acetylide $\left(\mathrm{C}_{2} \mathrm{HK}\right.$ or $\left.\mathrm{C}_{2} \mathrm{HCs}\right)$.

There is an extensive literature on methods of generating dispersions of fine solid particles or liquid droplets in fluid media, which are called aerosols (3). Most of the methods for obtaining aerosols of uniform concentration involve the passage of a steady stream of the fluid into which is fed at a constant rate the substance to be dispersed. There is usually a provision to ensure that the powder is prevented from agglomorating. For obvious reasons it is difficult to generate uniform aerosols in a stagnant gas such 
as is present in a detonation tube before the detonation is initiated. An aerosol, the concentration of which at a given section of the tube varies with time, can be easily generated. One simple way in which this can be done is by standing the detonation tube vertically and by infecting the powder with a small volume of high pressure gas at a point in the tube above the test section and letting the powder settle under gravity. Concentration as a function of time at a given point in the tube can be calculated by obtaining the weight accumulated at the bottom of the tube as a function of time. This can be done with a sensitive balance placed under the tube.

The electrical conductivity of a gas can be easily measured by measuring with a probe connected to an oscilloscope the voltage drop across the ionized gas and comparing it with the voltage drop across a known resistor. This method has been successfully used to measure gas conductivities of the order of $10^{-3}$ mhos/cm (1). At higher gas conductivities, however, it has been found (4) that surface effects complicate the situation and proper measurement is no longer possible. A satisfactory method of measuring high electrical conductivities using a magnetohydrodynamic interaction technique has been developed by Lin et al. (4). According to this method a field coil with its axis along the axis of the detonation tube sets up an axially symmetric magnetic field with radial components. The 
moving gas interacts with this radial field. As a result, a circumferential current which closes on itself flows in the gas. This current induces a magnetic field which links a 'search coll' placed close to the fleld coll. The change of this field with time due to the gas flow causes an induced voltage in the search coil circuit. This induced voltage is recorded on the oscilloscope as a function of time and from this curve the gas conductivity can be calculated with the help of suitable callbration.

The object of this thesis is to report the results of an investigation on ionization in seeded detonation waves. Using a vertical detonation tube aerosols of fine Potassium Acetylide $\left(\mathrm{C}_{2}\right.$ HKK $)$ were generated in 50-50 oxy-acetylene mixtures at 1/10 atmosphere initial pressure. The concentration of the powder at the test section was calculated from measurements of the accumulated weight at the bottom of the tube as a function of time. The electrical conductivity of the gas behind the detonation was measured by Iin's method mentioned above. The measured values were compared with theoretical results based on thermodynamic equilibrium calculations. 


\section{APPARATUS}

The description of the apparatus may be conveniently subdivided Into three parts as follows:

1) The detonation tube, gas filling system and Ignition system.

2) The aerosol generator and instrumentation for concentration determination.

3) Instrumentation for determining the electrical conductivity.

1) The detonation tube was made up of a 3 foot long stainless steel tube, two 3 foot Pyrex double-tough glass pipes $11 / 2^{\prime \prime}$ inside diameter and one 1 foot stainless steel tube thus giving a total run of ten feet. The tubes were joined together with speclal flanges, with Teflon gaskets and 0 -rings providing the sealing. The downstream end of the 1 foot steel tube was connected to a dump tank and separated from it by a cellophane diaphragm. The tube was mounted on an Aluminium channel $6^{\prime \prime}$ wide which was stood up vertically and supported by a steel channel and two steel angles. Gas manifold and storage systems were made of metal. Commercial Acetylene and oxygen were used directly without purification. Pressures were measured with a simple $U$ tube mercury manometer. Compositions of the mixtures were determined from partial pressures. Figure 1 shows schematically the layout of the tube and connections to the vacuum pump, manometer and filling 
system. Detonation waves were generated in the tube by spark initiation with the help of a Tesla coll.

2) The Aerosol Generator and instrumentation for concentration determination.

The aerosol was generated by injecting the powder into the detonation tube with a small volume $(3.12 \mathrm{cc})$ of $50 \mathrm{per}$ cent oxygen 50 per cent acetylene mixture which was not premixed. To break up the powder properly, high injection pressures forcing the powder through passages designed to give the flow high shear are required. An injection pressure of 60 psia was used as this was the limit up to which the acetylene could be compressed to yield a 50-50 mixture with oxygen. After some experimentation it was decided to use a 1/4" O.D. soft copper tube fitted with nozzles to introduce the powder into the tube. Nozzle size was varied to accommodate varying amounts of powder used in different experiments; 1/16", 1/8" dia and no nozzle, 1.e., 0.186" I.D. of tube were used. Powder was introduced downward in the tube at a point 3 feet from the top of the tube and 4 feet above the search coll as shown in FIg. 1. As the powder settled under gravity a separation according to size occurred and gave a powder concentration varying with both time and distance along the tube.

A sensitive balance designed by J. Tuzson (5) was used to record the weight of powder settling at the end of the tube as a function of time. From this curve the concentration 
of the powder at the test section can be computed as a function of time as shown in Appendix B. Deflections of the balance were read with a mirror telescope system and were proportional to the accumulated weight on the pan as determined by suitable calibration with known weights. With the telescope and scale about elght feet away from the mirror a deflection of $1 \mathrm{~mm}$ corresponded to a weight of about $1 \mathrm{mgm}$ on the pan. A typical accumulated welght versus time curve is shown in Fig. 2. Figure 3 shows the concentration of powder at the test section as a function of time for different amounts of powder injected. It also shows the average size of the particles present at the test section as a function of time. These curves were averages of several muns at each weight of injected powder. The scatter in the data was considerable and it is estimated that concentrations were determined to within a factor of two by the above method.

3) The method used to measure the electrical conductivity of the gas behind the detonation wave was first developed by Lin et al. (4). Figure 1 shows a schematic diagram of the apparatus. An axially symmetric radial magnetic field was provided at a glass section of the detonation tube by a simple d.c. coll the axis of which coincided with the axis of the detonation tube. The field coil consisted of 1200 turns of No. 17 (0.04526" dia.) enamelled annealed copper wire wound on a Bakelite coil-form of such dimensions that the resultant solenold had a length of $3.8 \mathrm{~cm}$. and a mean diameter 
of $11 \mathrm{~cm}$. The Bakelite coil-form had an inside diameter of $5.4 \mathrm{~cm}$ so that it could be fitted onto the glass section of the tube allowing about $3 \mathrm{~mm}$ clearance between it and the outside surface of the glass pipe. The resistance of the coil was measured to be about 7 ohms. Hence a current of about 10 amperes was provided by six 12 volt automobile batteries in series, which were used to energize the coil. The maximum axial field at this current was computed to be about 4000 gauss. Design details are given in Appendix A.

A small search coil was placed slightly upstream of the field coil to pick up the electromagnetic disturbance produced by the passage of the detonation wave through the magnetic field. The search coil was mounted on the coil-form which carried the field coil and was about 9/16" upstream to 1t. It consisted of 50 turns of No. 36 (0.005" dia.) enamelled annealed copper wire resulting in a single-layered coll $8 \mathrm{~mm}$ long and $5.7 \mathrm{~cm}$ diameter. As shown schematically in Fig. 4 the search coil was actually made up of two 25 turn coils wound side by side and connected in series. The junction point of the two coils was grounded and the two ends of the combined coil were connected to the differential preamplifier inputs $A$ and $B$ of the Tektronix 535 oscilloscope with a Type 53/54 D plug-in unit. The purpose of this centre-tap arrangement was to minimize electrostatic pickup discussed in detail in reference (4). The shunt input resistors (1000 ohms) were chosen to give approximately critical damping of the search coil circuit. Design details in Appendix A. 
To obtain the search coil voltage as a function of time when the detonation wave passes through the magnetic field, a single sweep from the oscilloscope mentioned above was used. The sweep was triggered by an ionization gage (a $10 \mathrm{~mm}$ automobile spark plug) located about a foot upstream of the field coil to detect the approach of the detonation wave.

From the voltage time response of the search coil the gas conductivity can be computed if the gas velocity and the coil geometry and field current are known. More conveniently the search coil may be calibrated by shooting a metallic slug through the magnetic field. The search coil response for a Dural slug used in the calibration is shown in Fig. 5. It is shown in Appendix A that the gas conductivity is given by

$$
\sigma=0.602 \frac{\phi}{\bar{u}}
$$

where $u$ is the gas velocity and $\phi$ is the area under the search coll response when the seeded detonation passes through the magnetic field. Detonation wave speeds for the mixtures used have been measured by Hogan (6), and found to agree with theoretical calculations. Hence, calculated gas velocities were used in deducing the conductivity from the above formula. 
III. THEORETICAL COMPUTATION OF THE ELECTRICAL CONDUCTIVITY

The theoretical computations were carried out in three steps as follows:

1) The pressure, temperature, velocity and composition of the gas behind the detonation wave was computed from the Chapman-Jouget theory of detonation waves (7).

2) Using Saha's equation (8) and the gas properties computed above, the fraction ionized was calculated.

3) From the fraction ionized the electrical conductivity of the gas was obtained using suitable electronmolecule and electron-ion collision cross sections.

1) For a given initial mixture composition, temperature and pressure; the pressure, temperature, velocity and composition of the gas behind the detonation wave can be calculated from the Chapman-Jouget theory using standard techniques (7). The inftial conditions were:

Composition: 50 per cent Acetylene 50 per cent Oxygen

Pressure: $\quad 0.1$ atmosphere

Temperature: $298.16^{\circ} \mathrm{K}$

The following species were considered in the products of combustion:, $\mathrm{CO}, \mathrm{O}, \mathrm{H}, \mathrm{OH}, \mathrm{C}_{\mathrm{g}}, \mathrm{CO}_{2}, \mathrm{C}_{2} \mathrm{H}_{2}, \mathrm{H}_{2}, \mathrm{O}_{2}, \mathrm{H}_{2} \mathrm{O}$. The solutions to the detonation equations were carried out on the IBM 704 computer at M.I.T., with the help of a program loaned by the Los Alamos Scientific Laboratory through the courtesy of Mr. R. E. Duff. In the calculations the equilibrium 
sound speed was used. To account for the presence of the additive an approximation was made and a fictitious inert gas $X$ was introduced in the program as part of the reactants. The compound $\mathrm{C}_{2} \mathrm{HK}$ was assumed to decompose in the detonation according to the following reaction:

$$
\mathrm{C}_{2} \mathrm{HK}=2 \mathrm{C}_{\text {solid }}+\mathrm{K}_{\text {gas }}+\frac{1}{2} \mathrm{H}+\frac{1}{4} \mathrm{H}_{2}+\Delta \mathrm{Q}
$$

The proportion of $\mathrm{H}_{2}$ to $\mathrm{H}$ was taken as $\frac{1}{2}$ since this is approximately their ratio in the combustion gases. The composition of the fictitious gas $X$ was assumed to be that given by the right hand side of the equation. $\Delta Q$ was computed from the heat of combustion of $\mathrm{C}_{2} \mathrm{HK}$ as measured in the laboratory and had the value $-84 \mathrm{KCal}$ per mole $\mathrm{C}_{2} \mathrm{HK}$. Hence to approximate the cooling effect of the powder the gas $X$ was given a heat of formation of $-\Delta Q / 1.75$ or $47 \mathrm{KCal} / \mathrm{mole}$. At mole fractions of Potassium below about $10^{-2}$ the carbon is present predominantly in the vapor phase and not as a solid as assumed above, but for these low mole fractions the effect of the additive in determining the gas temperature is small, hence the above assumption was still used for these cases. The initial pressure used in the program was such that the computed density involving the gas $X$ was equal to the actual density including the solid additive $\mathrm{C}_{2} \mathrm{HK}$. Figure 7 tabulates the amount of Potassium Acetylide required in the reactants, the mole fraction of 
the gas $X$ required in the reactants and the initial pressure of the reactants as a function of the mole fraction of Potassium in the gas behind the detonation. It also gives the properties such as molecular weight, specific heat at constant pressure and heat of formation of the gas $X$. Details of calculation are presented in Appendix $C$.

Figure 8 tabulates as a function of the mole fraction of Potassium in the gas, the gas properties behind the detonation as calculated according to the above method. The method of calculation of the conductivity is presented in the next two sections.

2) The equilibrium constant $\mathcal{K}$ for the ionization of $K$ according to the equation:

$$
\mathrm{K} \rightleftarrows \mathrm{K}^{+}+\mathrm{e}
$$

is given by Saha's equation as follows (8):

$$
\log _{10} \kappa=-(5040)(I) / T+2.5 \log _{10} T-6.49
$$

where I is the ionization potential of Potassium (4.318) in $\mathrm{eV}$ and $\mathrm{T}$ is the gas temperature in degrees Kelvin.

By definition

$$
\mathcal{K}=\left(\mathrm{p}_{\mathrm{e}}\right)\left(\mathrm{p}_{\mathrm{K}^{+}}\right) / \mathrm{p}_{\mathrm{K}}
$$

where $\mathrm{p}_{\mathrm{e}}, \mathrm{p}_{\mathrm{K}^{+}}$and $\mathrm{p}_{\mathrm{K}}$ are the partial pressures of the electrons, the ions and $K$ respectively, in atmospheres. Now if

$$
x=\frac{\text { initial number of moles of } K}{\text { total number of moles of gas }}
$$


$\mathrm{p}_{\mathrm{K}^{+}}+\mathrm{p}_{\mathrm{K}}=(\mathrm{x})(\mathrm{p})$ where $\mathrm{p}$ is the total pressure of the gas in atmospheres. Assuming $\mathrm{p}_{\mathrm{e}}=\mathrm{p}_{\mathrm{K}^{+}}$for electrical neutrality we have

$$
K=\left(p_{e}\right)^{2} / p_{K}=\frac{p_{e}^{2}}{\left(p x-p_{e}\right)}
$$

or

$$
p_{e}=\frac{-K+\sqrt{K^{2}+410 p}}{2}
$$

The fraction ionized ' $\alpha$ ' is given by

$$
\alpha=p_{e} / p
$$

3) The method of computing the conductivity from the fraction ionlzed and collision cross sections given here follows the presentation in reference 4. Theories for the electrical conductivity of gases have been developed for two extreme cases, viz. (a) the case of a slightly lonized gas where the close encounters between the electrons and the neutral atoms and molecules dominate the electron mobility and (b) the case of a completely ionized gas where the distant encounters between the ions is the controlling phenomenon. For a slightly ionized gas the electrical conductivity in mhos/cm is given by (9):

$$
\sigma=\frac{(0.532)(\alpha)(e)^{2}}{(9)(10) \sqrt[11]{\left(m_{e}\right)(k)(T)} \sum_{j} x_{j} Q_{j}}
$$

where 


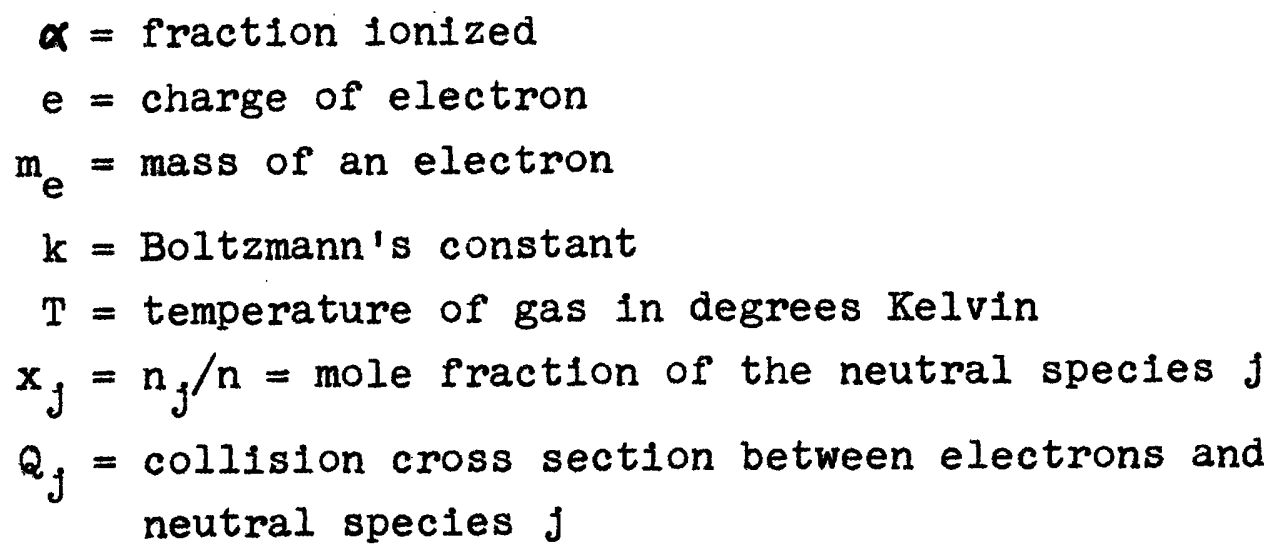

For a completely singly ionized gas the electrical conductivity is given by (10):

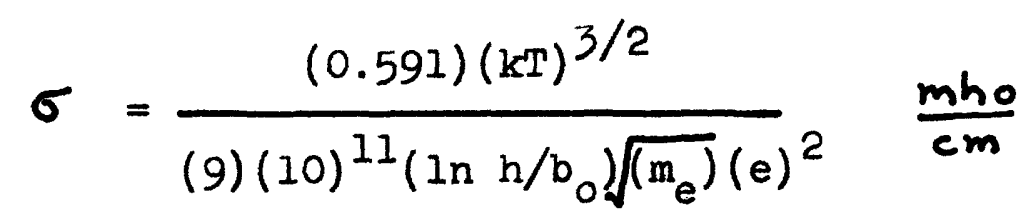

where

$$
h=\left(k T / 8 \pi n e e^{2}\right)^{1 / 2}
$$

is the Debye distance, and

$$
b_{0}=(e)^{2} / 3 k T
$$

is the impact parameter at which a positive ion deflects a mean energy electron 90 degrees.

If we consider the diffusion of electrons through the positive ions as a free path process then by comparing the two above formulae we find that an effective cross section for electrons and positive ions is:

$$
Q_{1}=8.1\left(b_{0}\right)^{2}\left(\operatorname{ln~} h / b_{0}\right) .
$$

Hence for intermediate degrees of ionization not covered by elther of the above formulae and within the range of our 
experiments, we make the approximation that

$$
\sigma=\frac{(0.532)(\alpha)(e)^{2}}{(9)(10)^{11}\left(m_{e} k T\right)^{1 / 2}\left(\sum_{j} x_{j} Q_{j}+\alpha Q_{i}\right)} \frac{\text { mho }}{c m}
$$

assuming

number of positive ions per $c c=$ number of electrons per cc. This method of computing the electrical conductivity for intermediate degrees of ionization has received some experimental support (4)(11). Substituting numerical values for me, e, $k$, etc., we finally obtain

$$
\sigma=3.84 \times 10^{-10} \frac{\alpha}{\sqrt{T}\left(\sum_{j} x_{j} Q_{j}+\alpha Q_{1}\right)} \quad \frac{m h o}{c m}
$$

The main constituents of the products of combustion behind the detonations under consideration were $\mathrm{CO}, \mathrm{H}$ and $\mathrm{H}_{2}$ all of which have collision cross sections with electrons of about $10^{-15} \mathrm{sq} \mathrm{cm}$ at electron temperatures of 3500 degrees Kelvin (12). Alkali metal atoms, however, have large cross sections - about $40(10)^{-15} \mathrm{sq} \mathrm{cm}$ for Potassium - at these temperatures (13), and when the fraction of additive is significant, say higher than 1 per cent, it contributes significantly to the summation $\sum_{j} x_{j} Q_{j}$. Hence $\sum_{j} x_{j} Q_{j}$ will consist of 2 terms $x_{g} Q_{g}$ and $x_{K} Q_{K}$ where $x_{K}$ is the mole fraction of neutral potassium atoms and $x_{g}$ is the mole fraction of the rest of the gas. Figure 9 tabulates the values of the fraction ionized $(a)$, the electron-ion collision cross section $\left(Q_{1}\right)$, 
the product $a Q_{1}$, the terms $x_{g} Q_{g}$ and $x_{K} Q_{K}$ and the electrical conductivity, for different mole fractions of Potassium in the gas.

With the above values for the collision cross sections the theoretical conductivity of the gas benind the detonation wave under equilibrium conditions was calculated according to the above equation and plotted in Fig. 10 as a function of the mole fraction of the additive Potassium. Similar calculations were also carried out for the additive Cesium, using the same data as in the case of Potassium with the exception of the lower ionization potential of Cesium (3.87 eV as compared to $4.318 \mathrm{eV}$ ). Figure 14 shows the plot for Cesium and Potassium for purposes of comparison.

For mole fractions of Potassium varying from $10^{-3}$ to $10^{-1}$, calculations were also carried out to study the effect of gas pressure and temperature on the conductivity of the gas. The gas composition was assumed to be that behind a 50-50 oxy-acetylene detonation at 1/10 atmosphere initial pressure. Figure 12 shows a plot of the conductivity versus mole fraction of $K$ for 3 different pressures $1 / 10,1$, and 10 atmospheres; and 2 different temperatures 4000, and , 6,000 degrees Kelvin. 


\section{RESULTS AND DISCUSSION}

The method by which the density of Potassium Acetylide was obtained as a function of time is explained in Appendix B.

Figure 3 shows a plot of the density of Potassium Acetylide at the test section as a function of time elapsed after injection, for various amounts of infected powder (40, $100,200$ and $300 \mathrm{mgm})$. The computed average particle size at the test section as a function of time is also shown in the same figure.

Conductivities were measured behind detonations initiated at different times after injection of powder. Figure 13 tabulates the measured values of conductivity for various amounts of injected powder as a function of time elapsed after injection. From figures 3 and 13 a cross plot of the conductivity as a function of the powder concentration (or mole fraction of Potassium) was obtained. Figure 10 shows these experimental points.

Figure 6 shows typlcal oscillograms obtained with the apparatus when seeded detonation waves passed through the magnetic field. Most oscillograms showed two peaks as in Fig. 6(b) rather than the single peak observed in Fig. 6(a). The final conductivity was therefore achleved in two steps in most of the experiments and it is this final conductivity which was used for comparison with theoretical results. The oscillograms also showed that the conductivity behind the 
detonation front is approximately constant for a period of at least 100 microseconds.

Figure 10 also shows the theoretical values of conductivity as a function of the mole fraction of Potassium in the product gases, which was varied from $10^{-3}$ to $10^{-1}$. There is a maximum in the curve which occurs at about 3 per cent Potassium. A lesser amount of Potassium produces fewer ions and hence lower conductivity. For larger amounts of Potassium the conductivity is lower for two reasons: first, the temperature of the detonation is lowered, and second, the relative values of $x_{K}$ and $\alpha$ change in such a way that there is an increase in the effective cross section. Figure 9 tabulates the contribution of the different species to the conductivity as a function of the mole fraction of Potassium.

A comparison between experimental and theoretical values of conductivity (Fig. 10) shows that they have approximately the same dependence on the mole fraction of Potassium. Absolute values agreed within a factor of two, the agreement improving with increasing mole fraction of Potassium. The maximum observed value of the conductivity was 2.7 mhos/cm. Two constant temperature lines corresponding to 3500 and 4000 degrees Kelvin were drawn in Fig. 10, to demonstrate the drop in gas temperature at high mole fractions of Potassium. At low concentrations where the effect of the additive in lowering the gas temperature is not 
important, it can be seen that the experimental points more or less follow a constant temperature line.

The discrepancy between theory and experiment at the lower mole fractions may be due to the fact that at low concentrations the additive particles are relatively far from each other and the electron clouds emanating from them do not get enough time to overlap during the time of the experiment, thus resulting in measured conductivities lower than theoretical. To get an idea of the diffusion times involved as a function of the mole fraction of Potassium, an approximate calculation was made assuming an average particle size of 10 microns. Figure 11 shows the results of this calculation as a $\log \log$ plot. Details of the calculation are given in Appendix D. The diffusion time falls from about 80 microseconds at 0.1 per cent $K$ to 17 microseconds at $I$ per cent $K$ to 3.5 microseconds at 10 per cent $K$. Since the duration of the experiment is about 100 microseconds there would be a gradual rise in conductivity behind the detonation front at the low concentrations, if the above effect were important. Since there was no such rise, this effect is probably negligible.

There is some uncertainty in the values of the collision cross sections used. At the temperatures under consideration $\left(3500-4000^{\circ} \mathrm{K}\right)$ measured values of cross sections are available only for electron $-\mathrm{H}_{2}$ collisions. For the other species of interest, $\mathrm{H}, \mathrm{CO}$ and $\mathrm{K}$, the cross sections had to be obtained 
by extrapolation of data reported for higher temperatures, which is a hazardous procedure at best, especially for co and $K$ which have sharp peaks near the temperatures of interest. It can be seen from Figure 9 that at low Potassium concentrations the electron-gas collision cross section $\mathrm{Q} g$ controls the conductivity while at high Potassium concentrations the electron-Potassium atom collision cross section $Q_{K}$ controls the conductivity. From the experimental data it would seem that the value of $Q_{K}$ is about right but that a higher value of $Q_{g}$ would give better agreement between theory and experiment. Therefore, Figure 14 was plotted using an electron-gas cross section of $2 \times 10^{-15} \mathrm{sq} \mathrm{cm}$ or twice the value used in plotting Figure 10, and this gave excellent agreement between theory and experiment.

On Figure 14 is also shown a theoretical curve for the additive Cesium, using exactly the same collision cross sections and other data as used for the Potassium calculations except for the ionization potential, which is $3.87 \mathrm{eV}$ for Cesium as opposed to $4.318 \mathrm{eV}$ for Potassium. The conductivities obtainable with Cesium are about a factor of two higher with a peak of 5 mhos/cm.

The search coil responses obtained in most experiments show two peaks, similar in shape, the second peak being on the average about 25 per cent of the first peak and trailing it by 7 to $23 \mathrm{~cm}$. The first peak corresponds to the passage of the detonation front; the second peak is probably due to 
a compression wave following the detonation front. The existence of such waves has been reported by Cher and Kistiakowski (17). Their presence has also been inferred from heat transfer measurements made simultaneously with the conductivity measurements reported here $(6)$. The nature of the lagging chemical reaction responsible for the presence of the second wave is unknown. Cher and Kistiakowsk1 speculated that the reaction probably involves carbon monoxide or carbon since these double waves were observed only in hydrocarbon-oxygen detonations and not in oxyhydrogen detonations. The data obtained by us shows that the presence of double waves was observed when Potassium Acetylide $\left(\mathrm{C}_{2} \mathrm{HK}\right)$ was used as seeding material and the distance between the two waves increased as the amount of additive increased. Since $\mathrm{C}_{2} \mathrm{HK}$ is likely to yleld carbon on decomposition it seems quite probable that the lagging chemical reaction responsible for the double waves involves carbon. Figure 13 lists the final conductivities obtaining behind the detonations as measured, together with the rise in conductivity in the second wave. Estimates of the temperature rise in the second wave obtained from the conductivity data are also tabulated.

To summarize:

1) Aerosols were generated in equimolal oxy-acetylene mixtures at 1/10 atmosphere initial pressure, with a finely ground Potassium compound called Potassium Acetylide. The 
density of the resulting aerosol was computed from a measurement of accumulated weight at the bottom of the detonation tube as a function of time. The error in these measurements was probably not more than 100 per cent.

2) Detonations were initiated in the aerosol and the electrical conductivity behind the detonation front was measured by a magnetohydrodynamic interaction technique. This required the measurement of an area on an osc1llogram and a knowledge of the gas velocity. The error in the area measurement is less than 10 per cent. Detonation wave speeds were measured to within 5 per cent accuracy and agreed well with calculated velocities. Hence calculated gas speeds were used in the data reduction and the error in this probably does not exceed 10 per cent.

3) The theoretical calculation of the conductivity involves the assumption of thermodynamic equilibrium with respect to ion formation in the gas, a knowledge of the gas temperature and pressure and the electron-gas, electronPotassium atom and effective electron-ion collision cross sections. The equilibrium assumption is in some doubt because of the presence of double waves, but the maximum error from this source probably does not exceed about 30 per cent which represents the conductivity rise in the second wave in the worst case. The computed gas pressure cannot be very far wrong because the speeds checked well with measurements and the initial density was correctly simulated to allow for 
the presence of the solid additive. The gas temperature is dependent mainiy on the enthalpy change in the chemical reaction and since this was properly simulated errors of more than 5 per cent are highly unlikely. This means that the largest source of error is probably in the collision cross sections used. The electron-1on collision cross section is not a dominant term in the conductivity equation at any mole fraction of Potassium investigated, so that the electron gas and electron-Potassium atom collision cross sections are probably the ones in error. Since the former is dominant at low mole fractions where the discrepancy between theory and experiment is large, and since at the temperatures in question its value is not known elther from scattering theory or from experimental measurements it must be concluded that the electron gas collision cross section is more like $2 \times 10^{-15} \mathrm{sq} \mathrm{cm}$ than $1 \times 10^{-15} \mathrm{sq} \mathrm{cm}$. 


\section{APPENDIX A}

MEASUREMENT OF THE ELECTRICAL CONDUCTIVITY

BY THE MAGNETIC METHOD

1. Field coil design

2. Search coil design

3. Calibration of search coil response

1. Field coil design

The maximum fleld produced by the field coil must

be appreciably lower than that at which the cyclotron frequency of the electrons in the gas is of the same order as the collision frequency of the electrons with atoms and molecules, so that the electrons are not confined by the magnetic field.

The collision frequency is given by

$$
\nu=v / l
$$

where

$$
\begin{aligned}
& \mathbf{v}=\text { mean velocity of electrons } \\
& \boldsymbol{l}=\text { mean free path of electrons }
\end{aligned}
$$

But

$$
\mathrm{v}=(8 \mathrm{kT} / \pi \mathrm{m})^{1 / 2} \text { and } \boldsymbol{l}=1 / \mathrm{nQ}=\mathrm{kT} / \mathrm{pQ}
$$

where

$$
\begin{aligned}
& \mathrm{k}=\text { Boltzmann's constant } \\
& \mathrm{T}=\text { gas temperature in }{ }^{\circ} \mathrm{K} \\
& \mathrm{m}=\text { electron mass } \\
& \mathrm{n}=\text { number density of atoms and molecules } \\
& \mathrm{Q}=\text { collision cross section } \\
& \mathrm{p}=\text { gas pressure }
\end{aligned}
$$


Therefore

$$
\begin{aligned}
\text { collision frequency } & =\left(8 \mathrm{kT} / \pi_{\mathrm{m}}\right)^{1 / 2} \mathrm{nQ} \\
& =\left(8 / \pi_{\mathrm{mkT}}\right)^{1 / 2} \mathrm{pQ}
\end{aligned}
$$

Putting in the values of $\mathrm{k}, \mathrm{m}$ and $\pi$ and taking $\mathrm{p}=4 \mathrm{~atm}$, $\mathrm{T}=3500^{\circ} \mathrm{K}, Q=10^{-15} \mathrm{sq} \mathrm{cm}$, we get the collision frequency as $3 \times 10^{11} \mathrm{sec}^{-1}$.

The cyclotron frequency is given by

$$
\nu^{\prime}=\mathrm{eB} / \mathrm{m}
$$

where

$$
\begin{aligned}
& \mathrm{e}=\text { charge of electron } \\
& B=\text { magnetic field strength }
\end{aligned}
$$

Putting in the values of $e$ and $m$ and taking care of units we get

$$
\nu^{\prime}=1.76 \times 10^{7} \mathrm{~B} \mathrm{sec}^{-1} \text { where } \mathrm{B} \text { is in gauss. }
$$

Equating the two frequencies we have the limiting value of B as 20,000 gauss approximately.

Hence it was decided to design the field coil for about 4000 gauss maximum field strength.

$$
\begin{aligned}
& B=4000 \text { gauss }=0.4 \text { weber } / \mathrm{sq} \text { meter } \\
& H=B / \mu=0.4 / 4 \pi(10)^{-7}=3.2 \times 10^{5} \mathrm{amp} / \text { meter }
\end{aligned}
$$

Now

$$
\mathrm{H}=\mathrm{NI}
$$

where

$$
\begin{aligned}
& \mathrm{H}=\text { magnetic field intensity } \\
& \mathrm{N}=\text { number of turns per meter } \\
& \mathrm{I}=\text { current in amps }
\end{aligned}
$$


Hence assuming a current of 10 amps we have

$$
\begin{aligned}
N=H / I=3.2(10)^{5} / 10= & 32,000 \text { turns per meter } \\
& \text { or } 320 \text { turns per } \mathrm{cm}
\end{aligned}
$$

Assuming length of coil $=1 . d$. of detonation tube $=3.86 \mathrm{~cm}$ we get total number of turns $=320 \times 3.86=1235$ turns.

The coil resistance must be less than say 10 ohms so that the power supply needed to supply the field current will not be too large. Choosing No. 17 enamelled copper wire of diameter 0.04526 inches we can calculate the coll dimensions and its resistance.

I.D. of $\mathrm{coil}=5.7 \mathrm{~cm}$

O.D. of coil $=5.7+2\left(320 \times 0.04526^{2} \times 2.54^{2}\right)=14.0 \mathrm{~cm}$ approx. Allowing $1.0 \mathrm{~cm}$ for insulation we get $0 . D$. of $\operatorname{coll}=15 \mathrm{~cm}$ Mean dia of coil $=(5.7+15.0) / 2=10.35 \mathrm{~cm}$ Length of wire $1=\pi(10.35)(1235)=40400 \mathrm{~cm}=404$ meters Resistance of coil $=p\left(1 / \pi r^{2}\right)=1.7 \times 10^{-8} \times 404 / 00.1609 \times$ $\mathrm{x} 0.0254^{2}=6.62$ ohms

Now the actual maximum field $\mathrm{H}$ can be computed from the formula

$$
H=G\left(w \lambda / p a_{1}\right)
$$

where

$$
\begin{aligned}
& G=\left(\frac{2 \pi}{5} \frac{\beta}{\alpha^{2}-1}\right)^{1 / 2} \ln \left(\frac{\alpha+\left(\beta^{2}+\alpha^{2}\right)^{1 / 2}}{1+\left(\beta^{2}+1\right)^{1 / 2}}\right) \\
& 2 a_{1}=\text { internal radius of coil } \\
& 2 a_{2}=\text { external radius of coil } \\
& 2 b^{2}=\text { length of coil }
\end{aligned}
$$




$$
\begin{aligned}
& a=a_{2} / a_{1} \\
& \beta=b / a_{1} \\
& W=\text { power dissipated in the coil } \\
& p=\text { specific resistivity of copper } \\
& \lambda=\text { ratio of volume of copper to total volume of coil }
\end{aligned}
$$

Substituting the values involved we get the field as approximately 4000 gauss.

\section{Search coil design}

The response of the search coil is proportional to the number of turns in the coil but so is the risetime, so that a compromise is involved. The risetime is given by (LC) $)^{1 / 2}$ where $L$ is the inductance of the coil and $C$ is the input capacitance of the oscilloscope. Assuming the coil risetime to be of the same order as the oscilloscope risetime of $10^{-7}$ seconds and substituting the capacitance $(=47 \mu \mu \mathrm{F})$ we get the inductance of the coil to be 260 micro-Henries approx. Following Lin a single layer coil made up of 50 turns of No. $36\left(0.005^{\prime \prime} \mathrm{d} 1 \mathrm{a}\right)$ enamelled copper wire was used. The inductance of this coil works out to (15):

$$
L=0.001 \mathrm{~F} \times \mathrm{d} \times \mathrm{N}^{2}
$$

where

$$
\begin{aligned}
\mathrm{L}= & \text { inductance in micro Henries } \\
\mathrm{d}= & \text { coil diameter } \\
\mathrm{b}= & \text { coil width } \\
\mathrm{N}= & \text { total number of turns } \\
\mathrm{F}= & \text { a constant depending only on the width/diameter } \\
& \text { ratio and tabulated }
\end{aligned}
$$


Putting $\mathrm{N}=50, \mathrm{~d}=5.7 \mathrm{~cm}$ and $\mathrm{F}=18$ for $\mathrm{b} / \mathrm{d}=0.8 / 5.72=$ 0.14 , we get $\mathrm{L}=258$ micro Henries. Hence this coil is satisfactory. To minimize electrostatic pickup as discussed in detail in reference a centre-tap arrangement was used as shown in Fig. 4. The coil was actually made up of two 25 turn coils wound side by side and connected in series with their junction point grounded. The two ends of the coil were connected to the $A$ and $B$ inputs of the Tektronix High Gain Differential Preamplifier Type 53/54D which was used with the Tektronix oscilloscope type 535. The shunt input resistors were chosen to give approximately critical damping of the search coil circuit. Thus the resistance $R=2(L / C)^{1 / 2}=1000$ ohms approx.

3. Calibration of search coil response

The ratio between the maximum electrical conductivity attained by the gas $(\sigma)$ behind the detonation wave and the conductivity of the metallic slug used $\left(\sigma_{S}\right)$ to calibrate it is given by

$$
\sigma / \sigma_{s}=\frac{u_{s} \phi}{u \phi_{s}}
$$

where

$$
\begin{aligned}
\phi_{\mathrm{s}}, \varnothing= & \text { area under the voltage time response of the } \\
& \text { search coil for the calibration and the } \\
& \text { detonation, respectively } \\
u_{\mathrm{s}}, u= & \text { velocity of calibrating slug and particle } \\
& \text { velocity of gases behind detonation wave, } \\
& \text { respectively }
\end{aligned}
$$

The metallic slug used to calibrate the search coll was an 
aluminium alloy rod 6 inches long and $11 / 2$ inches diameter. It was machined from No. 202 T4 Dural bar stock so that 1t fitted with a small clearance in the glass pipe used as the detonation tube. The electrical conductivity of this material is listed in the ASME Handbook (14) as $1.77 \times 10^{5}$ mhos/cm at room temperature. The slug was catapulted through the magnetic field with the glass pipe as guide elther with the use of a stretched rubber band or by compressed air such that it swept through the magnetic field at approximately constant velocity. The velocity was measured by dividing the length of the slug by the time elapsed between the occurrence of the front and rear pulse in the oscillogram. Figure 5 shows a typical search coil response obtained by the above method.

Substituting the values for the.slug speed, area under the voltage time curve for the slug and the conductivity of Dural, we get

$$
\sigma=0.602 \frac{\phi}{u}
$$

from which the gas conductivity can be calculated from a knowledge of the velocity $u$ of the gas behind the detonation wave, and the area under the search coll response $\phi$ when the seeded detonation passes through the magnetic field. 


\section{APPENDIX B}

CALCULATION OF POWDER CONCENTRATION AT THE TEST

SECTION AS A FUNCTION OF TIME

The powder concentration at the test section as a function of time can be directly obtained from the accumulated weight-time curve as follows: Assuming that the only force resisting the fall of a particle under the force of gravity is frictional force due to the viscosity of the gas, we obtain by the use of Stoke's law (16) the terminal velocity of the falling particle as

$$
v=\frac{\rho g d^{2}}{18 \mu}
$$

where

$$
\begin{aligned}
& g=\text { acceleration due to gravity } \\
& \rho=\text { density of particle material } \\
& d=\text { particle diameter } \\
& \mu=\text { viscosity of gas }
\end{aligned}
$$

wherein the density of the gas has been neglected in comparison with the density of the falling particles of Potassium Acetylide. Substituting for the acceleration due to gravity, the viscosity of the gas at room temperature and the density of Potassium Acetylide (measured in our laboratory to be $1.2 \mathrm{gm} / \mathrm{cc}$ ) we get after taking care of the units

$$
v=0.0071 \mathrm{~d}^{2} \text { feet/minute }
$$

where $d$ is in microns ( 1 micron $=10^{-4} \mathrm{~cm}$ ). Denoting by 
I the distance between the point of injection and the pan of the balance we get

$$
\mathrm{t}=\mathrm{L} / \mathrm{v}
$$

where $t$ is the time after injection in minutes. Substituting for $v$ we get

$$
t=140 \mathrm{~L} / \mathrm{d}^{2}
$$

Since $L$ is known ( 7 feet), one can convert the accumulated weight vs. time curve obtained experimentally into an accumulated weight vs. particle diameter curve by using (2).

An average value for the concentration at the test section will be calculated by dividing the weight of powder present at time $t$ in a foot length of the pipe behind the test section by the volume of the gas contained in that length.

If the distance between the point of injection and the search coll be denoted by $x$, then the diameter of the largest particles which have just arrived at the test section at time $t$ is given by

$$
d_{1}^{2}=\frac{x}{t}(140)
$$

and the diameter of the largest particles which are one foot behind the above is given by

$$
d_{2}^{2}=\frac{(x-1)}{t}(140)
$$

$\mathbf{x}$ was measured to be 3.5 feet. The weight of powder present in the foot length can, therefore, be directly obtained from 
the curve of accumulated weight versus particle diameter, by taking the difference in the welghts $w_{1}$ and $w_{2}$ corresponding to the diameters $d_{1}$ and $d_{2}$, respectively. Denoting this difference by $\Delta w$, the concentration in mgms/liter is given by $\Delta w / 0.348$ or $2.87 \Delta w ; 0.348$ liters being the volume of one foot length of $11 / 2^{\prime \prime} 1 . d$. pipe. 


\section{APPENDIX C}

APPROXIMATE METHOD FOR ACCOUNTING FOR THE PRESENCE

OF SOLID ADDITIVE IN THE REACTANTS

1. Let

$$
x=\frac{\text { number of moles of potassium }}{\text { number of moles of gas in the reactants }}
$$

Density of reactants at 0.1 atmosphere pressure $=1 / 2.24(10)^{5}$ moles $/ \mathrm{cc}$

Molecular weight of Potassium Acetylide $\left(\mathrm{C}_{2} \mathrm{HK}\right)=(2)(12)+1+39=64$

Atomic weight of Potassium $=39$

If $\mathrm{m}$ gm of $\mathrm{C}_{2} \mathrm{HK}$ are in a volume $\mathrm{V} c \mathrm{c}$ of reactants then there are $(39 / 64)(\mathrm{m} / \mathrm{V}) \mathrm{gm} K$ per cc of reactants. Hence there are $(39 / 64)(\mathrm{m} / \mathrm{V})(1 / 39)$ moles of $\mathrm{K}$ per cc of reactants or

Density of Potassium $=(1 / 64)(\mathrm{m} / \mathrm{V})$ moles $/ \mathrm{cc}$ of reactants Therefore,

$$
x=(1 / 64)(\mathrm{m} / \mathrm{V})(2.24)(10)^{5}
$$

or

$$
\begin{aligned}
\mathrm{m} / \mathrm{V} & =2.86(10)^{-4}(\mathrm{x}) \mathrm{gm} / \mathrm{cc} \\
& =286(\mathrm{x}) \mathrm{mgm} / \text { liter }
\end{aligned}
$$

2. Let us assume that behind the detonation the $\mathrm{C}_{2} \mathrm{HK}$ dissociates as follows:

$$
\left(\mathrm{C}_{2} \mathrm{HK}\right)_{\mathrm{s}}=2 \mathrm{C}_{\mathrm{s}}+\mathrm{K}_{\mathrm{g}}+\frac{1}{2} \mathrm{H}+\frac{1}{4} \mathrm{H}_{2}+\Delta \mathrm{Q} \quad \begin{aligned}
& \mathrm{g}: \text { gas } \\
& \mathrm{s}: \text { solid }
\end{aligned}
$$

so that the composition of the fictitious gas $X$ is given by the right hand side of the above equation and its heat of formation by the quantity $-\Delta Q / 1.75 \mathrm{KCal} / \mathrm{mole}$. The heat of 
combustion of $\mathrm{C}_{2} \mathrm{HK}$ has been measured in our laboratory (measurements were made by $\mathrm{Mr}$. Lucien Donadieu, who also prepared the $\mathrm{C}_{2} \mathrm{HK}$ powder and studied some of its other properties) to be $277 \mathrm{KCal} / \mathrm{mole}$ for the following reaction:

$$
\left(\mathrm{C}_{2} \mathrm{HK}\right)_{\mathrm{s}}+5 / 2 \mathrm{O}_{2}=\frac{1}{2}\left(\mathrm{~K}_{2} \mathrm{CO}_{3}\right)_{5}+3 / 2 \mathrm{CO}_{2}+\frac{1}{2} \mathrm{H}_{2} \mathrm{O}
$$

from which the heat of formation of $\mathrm{C}_{2} \mathrm{HK}$ is calculated to be $-37 \mathrm{KCal} / \mathrm{mole}$. Using heats of vaporization of $\mathrm{C}_{\mathrm{s}}$ and $\mathrm{K}_{\mathrm{s}}$ and the heat of dissociation of $\mathrm{H}_{2}$ as given in reference 7 , page 742 , we obtain the value of $\Delta Q=-84 \mathrm{KCal} / \mathrm{mole}$. Hence heat of formation of $\mathrm{X}=47 \mathrm{KCal} / \mathrm{mole}$.

Molecular welght of $X=(2)(12)+39\left(\frac{1}{2}\right)(1)+\left(\frac{1}{4}\right)(2) / 1.75=36.6$

Specific Heat of $X$ at constant pressure $=(1.5)(2.5)+\left(\frac{1}{4}\right)(3.5) / 1.75$

$$
=2.64 \mathrm{R} \mathrm{Cal} / \mathrm{mole}
$$

\section{Let}

$$
x^{\prime}=\frac{\text { number of moles of Potassium }}{\text { number of moles of product gases }}
$$

and

$$
n_{\mathrm{K}}=\text { number of moles Potassium }
$$

Now from calculations on unseeded detonations we know that

$$
\frac{\text { number of moles of product gases }}{\text { number of moles of reactant gases }}=1.74=\frac{1}{0.575}
$$

Hence

$$
x=\frac{n_{K}}{0.575+n_{K}} \text { and } x^{\prime}=\frac{n_{K}}{1+n_{K}}
$$

Eliminating $\mathrm{n}_{K}$, we get 


$$
\frac{x}{1-x}=\frac{1.74 x^{\prime}}{1-x^{\prime}}
$$

so that

$$
x=\frac{1.74 x^{\prime}}{1+0.7^{4} x^{\prime}}
$$

Now one mole of $K$ corresponds to one mole of $\mathrm{C}_{2} \mathrm{HK}$ which corresponds to 1.75 moles of gas $x$. Hence the mole fraction of gas $X$ required in the reactants $\left(x_{X}\right)$ to simulate the mole fraction $x^{\prime}$ of $K$ in the products is given by $x_{X}=1.74 x$ or

$$
\begin{aligned}
x_{X} & =(1.74)^{2} \frac{x^{\prime}}{1+0.74 x^{\prime}} \\
& =\frac{3.02 x^{\prime}}{1+0.74 x}
\end{aligned}
$$

4. The initial pressure was calculated on the assumption that the inftial density involving the gas $\mathrm{X}$ was equal to the actual initial density involving the solid additive $\mathrm{C}_{2} \mathrm{HK}$.

Now the actual initial density is given by

$$
\rho_{1}=\frac{\mathrm{M}_{1} \mathrm{p}_{1}}{\mathrm{RT}_{1}}+2.86(10)^{-4} x
$$

where

$$
\begin{aligned}
\mathrm{M}_{1} & =\text { Molecular weight of the } 50-50 \text { oxy-acetylene mixture } \\
& =29 \\
\mathrm{p}_{1} & =\text { actual initial pressure } \\
& =0.1 \text { atm } \\
\mathrm{R} & =\text { Gas constant } \\
& =1.986 \frac{\mathrm{cal}}{\mathrm{gm} \text {-mole- } \mathrm{K}} \\
\mathrm{T}_{1} & =\text { initial temperature } \\
& =298.16^{\circ} \mathrm{K} \\
\mathrm{x} & =\text { mole fraction of Potassium in the reactants }
\end{aligned}
$$


The simulated density is given by

$$
\rho_{1}=\frac{p_{i} \sum_{i} M_{i} x_{i}}{R T_{1}}
$$

where

$$
\begin{aligned}
& \mathrm{p}_{1}=\text { the pressure to be used to account for the } \\
& \text { density change due to the additive } \\
& \mathrm{x}_{1}=\text { mole fractions of } \mathrm{C}_{2} \mathrm{H}_{2}, \mathrm{O}_{2} \text { and } \mathrm{x} \\
& \mathrm{M}_{1}=\text { molecular weights of } \mathrm{C}_{2} \mathrm{H}_{2}, \mathrm{O}_{2} \text { and } \mathrm{x}
\end{aligned}
$$

Hence

$$
\mathrm{p}_{1} \frac{\sum_{1} \mathrm{M}_{1} \mathrm{x}_{1}}{\mathrm{RT}_{1}}=\frac{\mathrm{M}_{1} \mathrm{p}_{1}}{\mathrm{RT}_{1}}+2.86(10)^{-4} \mathrm{x}
$$

or

$$
p_{i}=\frac{\mathrm{RT}_{1}}{\sum_{1} \mathrm{M}_{1} \mathrm{x}_{1}}\left(\frac{\mathrm{M}_{1} \mathrm{p}_{1}}{\mathrm{RT}_{1}}+2.86(10)^{-4} \mathrm{x}\right)
$$

Thus for a given $x^{\prime}$, the quantities $x_{X}$ and $p_{i}^{\prime}$ can be computed. Figure 7 tabulates $x, m / v, x_{X}$ and $p_{i}$ as a function of $x^{\prime}$.

5. In the reaction

$$
\mathrm{C}_{2} \mathrm{HK} \rightleftharpoons 2 \mathrm{C}+\mathrm{K}_{\mathrm{g}}+\frac{1}{2} \mathrm{H}+\frac{1}{4} \mathrm{H}_{2}
$$

the phase in which the carbon is present (whether solid or vapor) is dependent on the vapor pressure of the solid carbon (i.e., the gas temperature), the gas pressure, and the amount of carbon present in the system. At mole fractions of Potassium above about $10^{-2}$ the carbon would be present predominantly in the solid phase. At mole fractions of 
Potassium lower than about $10^{-2}$ the carbon would be present predominantly in the vapor phase contrary to the calculations presented above. However, at these low mole fractions the effect of the additive in determining the gas temperature is small, and hence the above method of calculation was still used for these cases. 


\section{APPENDIX D \\ CALCULATION OF DIFFUSION TIME OF POTASSIUM \\ VAPOR IN THE PRODUCT GASES}

Since most of the experiments were performed with particle size varying from 5 microns to 20 microns an average size of 10 microns was selected for this calculation.

It is shown in Appendix $B$ that the mass of additive required per unit volume of reactants $(\mathrm{m} / \mathrm{v})$ to give a mole fraction $x$ of Potassium in the reactant gases is given by

$$
\begin{aligned}
& \frac{m}{\bar{V}}=2.86 \times 10^{-4}(x) \\
& \text { Number of } 10 \text { micron particles per cc of reactants } \\
& =\frac{m}{\bar{V}} \times \frac{1}{\frac{4}{3} \pi r^{3} p} \\
& =\frac{2.86 \times 10^{-4}(x)}{\frac{4}{3} \pi r^{3} \rho}
\end{aligned}
$$

where

$$
\begin{aligned}
& r=\text { radius of particle in } \mathrm{cm} \\
& \rho=\text { density of additive in } \mathrm{gm} / \mathrm{cc}
\end{aligned}
$$

Putting

$$
r=5 \times 10^{-4} \mathrm{~cm} \text { and } \rho=1.2
$$

we get the concentration of additive $=(4.54)(10)^{5} \times \begin{gathered}\text { particles } \\ \text { cc }\end{gathered}$ Assuming these are uniformly distributed in the gas 
we have interparticle distance

$$
\xi=\frac{1}{4.54 \times 10^{5} \times^{1 / 3}} \mathrm{~cm}
$$

or

$$
=(1.3)(10)^{-2} x^{-1 / 3}
$$

The diffusion time $\tau$ is approximately given by

$$
\tau=\frac{\xi^{2}}{4 D_{K G}} \sec
$$

when $D_{K G}$ is the coefficient of diffusion for Potassium vapor in the product gases in $\mathrm{cm}^{2} / \mathrm{sec}$.

$$
\text { For rigid spheres } D_{K G} \text { is given by (18) }
$$$$
D_{\mathrm{KG}}=\frac{3}{8} \sqrt{\frac{\pi}{2}} \frac{1}{\mathrm{nQ}_{\mathrm{D}}}\left(\frac{\mathrm{m}_{\mathrm{K}}+\mathrm{m}_{\mathrm{G}}}{\mathrm{m}_{\mathrm{K}} \mathrm{m}_{\mathrm{G}}}\right)^{1 / 2} \frac{\mathrm{cm}^{2}}{\mathrm{sec}}
$$

where

$$
\mathrm{n}=\frac{\mathrm{p}}{\mathrm{kT}}=\text { number of density of gas }
$$

or

$$
D_{K G}=\frac{3}{8} \sqrt{\frac{\pi}{2}} \frac{(k T)^{3 / 2}}{p Q_{D}}\left(\frac{m_{K}+m_{G}}{m_{K} m_{G}}\right)^{1 / 2}
$$

when

$$
\begin{aligned}
& m_{K}=\text { mass of } \mathrm{K} \text { atom } \\
& m_{G}=\text { mass of gas atom } \\
& Q_{D}=\text { appropriate diffusion cross section }
\end{aligned}
$$

Using the atomic weight of Potassium (39), the molecular weight of the product gases (29) and a value of $3 \times 10^{-16} \mathrm{sq} \mathrm{cm}$ 
for $Q_{D}$ we get

$$
D_{\mathrm{KG}} \approx 40 \frac{\mathrm{cm}^{2}}{\mathrm{sec}}
$$

Substituting for $D_{K G}$ we get

$$
\begin{aligned}
\tau & =\frac{\xi^{2}}{160} \sec \\
& =\frac{(1.3)^{2}\left(10^{-2}\right)^{2} x^{-2 / 3}}{160} \\
& =1.056 \times 10^{-6} x^{-2 / 3}
\end{aligned}
$$

Substituting for $\mathrm{x}$ in terms of $\mathrm{x}^{\prime}$ the mole fraction of Potassium in product gases we get

$$
\tau=1.056 \times 10^{-6}\left(\frac{1.74 x^{\prime}}{1+0.74 x^{\prime}}\right)^{-2 / 3}
$$

Figure 11 shows this equation plotted on $\log -10 \mathrm{~g}$ paper. 


\section{RE FERENCES}

1. S. Basu and J. A. Fay, Seventh Symposium (International) on Combustion (Butterworths Scientific Publications, London, 1959), p. 277.

2. H. Belcher and T. M. Sugden, Proc. Roy. Soc. (London) A202, 17 (1950).

3. L. Silverman, Air Pollution Handbook - P. L. Magill, F. R. Holden and C. Ackley, editors (McGraw-Hill Book Co., New York, 1956), Section 12.

4. S. C. Lin, E. I. Resler and A. Kantrowitz, J. Appl. Phys. 26, 95 (1955).

5. J. Tuzson, Sc.D. Thesis in Mechanical Engineering (Massachusetts Institute of Technology, Cambridge, Massachusetts, U.S.A., 1959).

6. W. T. Hogan, S.M. Thesis in Mechanical Engineering (Massachusetts Institute of Technology, Cambridge, Massachusetts, U.S.A., 1959).

7. B. Lewis and G. von Elbe, Combustion, Flames and Explosions of Gases (Academic Press, New York, 1951), p. 606.

8. M. N. Saha and N. K. Saha, A Treatise on Modern Physics (The Indian Press, Allahabad and Calcutta, 1934), p. 630.

9. H. A. Lorentz, The Theory of Electrons (Dover Publications, New York, 1952), p. 67. S. Chapman and T. G. Cowling, The Mathematical Theory of Non-Uniform Gases (Cambridge University Press, London, 1952), Sections 18.12 and 14.2 and Table 6, Section 10.53 .

10. L. Spitzer and R. Harm, Phys. Rev. 89, 77 (1953).

11. S. C. Lin and L. Lamb, J. Appl. Phys. 28, 754 (1957).

12. H. S. W. Massey and E. H. S. Burhop, Electronic and Ionic Impact Phenomena (Oxford University Press, London, 1952), p. 206. 
REFERENCES (continued)

13. R. B. Brode, Revs. Modern Phys. 5, 257 (1933).

14. ASME Handbook, Metals Properties (McGraw-Hill Book Co., New York, 1954), p. 347.

15. F. W. Grover, Inductance Calculations (D. Van Nostrand Co., 1946), p. 153.

16. C. Orr, Jr., and J. M. Dallavalle, Fine Particle Measurement (The Macmillan Company, New York, 1959), p. 44.

17. M. Cher and G. B. Kistiakowsky, J. Chem. Phys. 29, 506 (1958).

18. E. H. Kennard, Kinetic Theory of Gases (McGraw-Hill Book Company, New York, 1938), p. 194.

19. F. W. Bitter, Currents, Flelds and Particles (Technology Press of M.I.T. and John Wiley and Sons, New York, 1956), p. 223. 


\section{BIOGRAPHICAL NOTE}

The author was born to Subodh Kumar and Abha Basu in September, 1933, at Calcutta, Ind1a. He was educated at the Balak Mandir School in Bombay, the Shivaji Military School in Poona and the Don Bosco High School in Bombay and passed the Secondary School Certificate Examination of the State of Bombay in 1949. He then entered the University of Bombay, where he attended the St. Xavier's College, 1949-1951, and the Victoria Jubilee Technical Institute, 1951-1954, graduating with First Class Honours in 1954, in the fleld of Mechanical Engineering. He joined M.I.T. in September, 1954, and worked as a Research Assistant in the Lubrication Laboratory while working for the S.M. degree in Mechanical Engineering, which he received in September, 1955. From September, 1955, to September, 1956, he was on the Engineering Training Programme of the General Electric Company, U.S.A. In September, 1956 he returned to M.I.T. as a Research Assistant in the Heat Division of the Mechanical Engineering Department and began work on Ionization in Detonation Waves. 


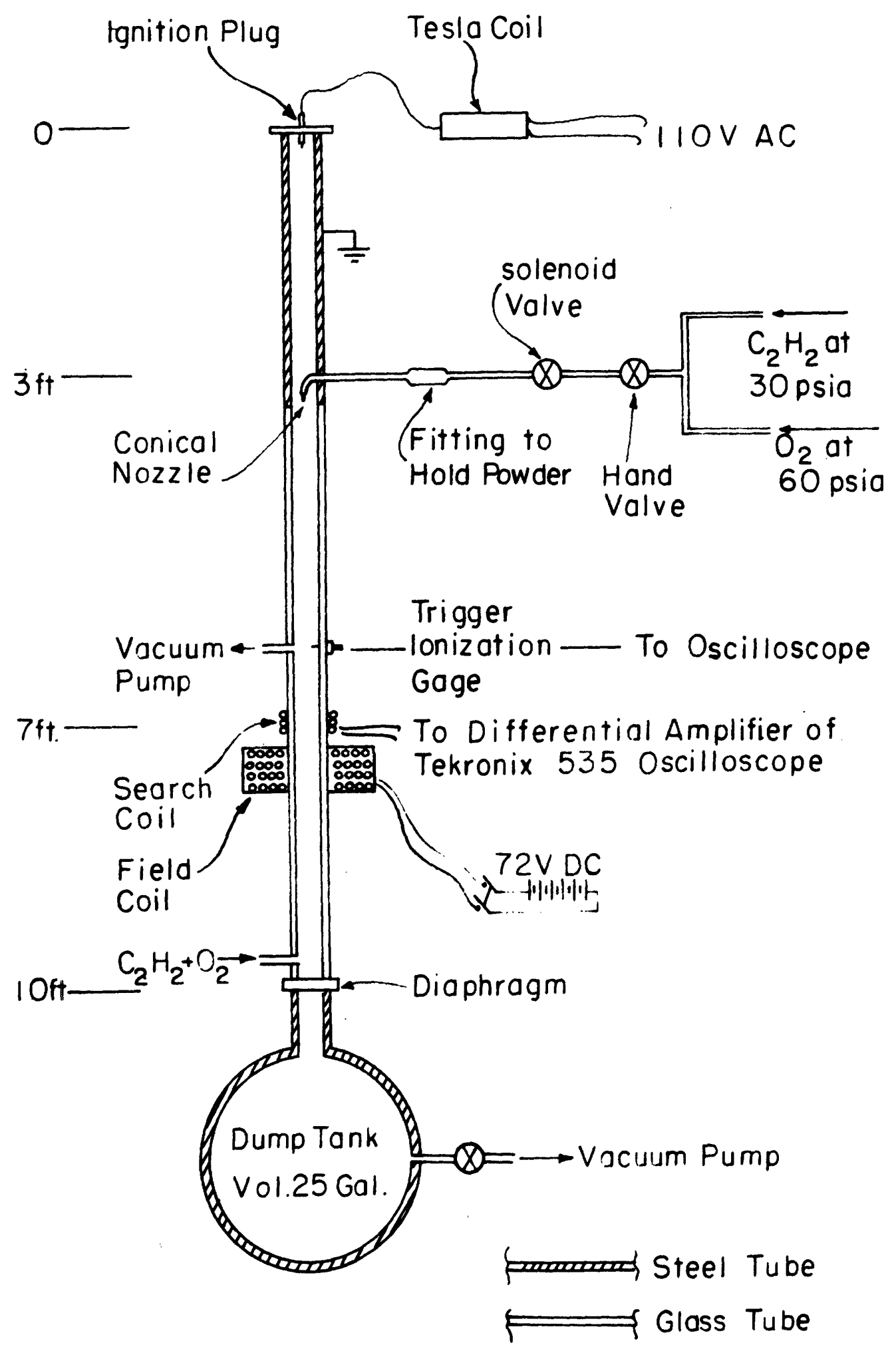

Figure 1

Schematic Diagram of Detonation Tube, Gas Connexions, Poweder Injection system, and Instrumentation for Measuring Conductivity. 


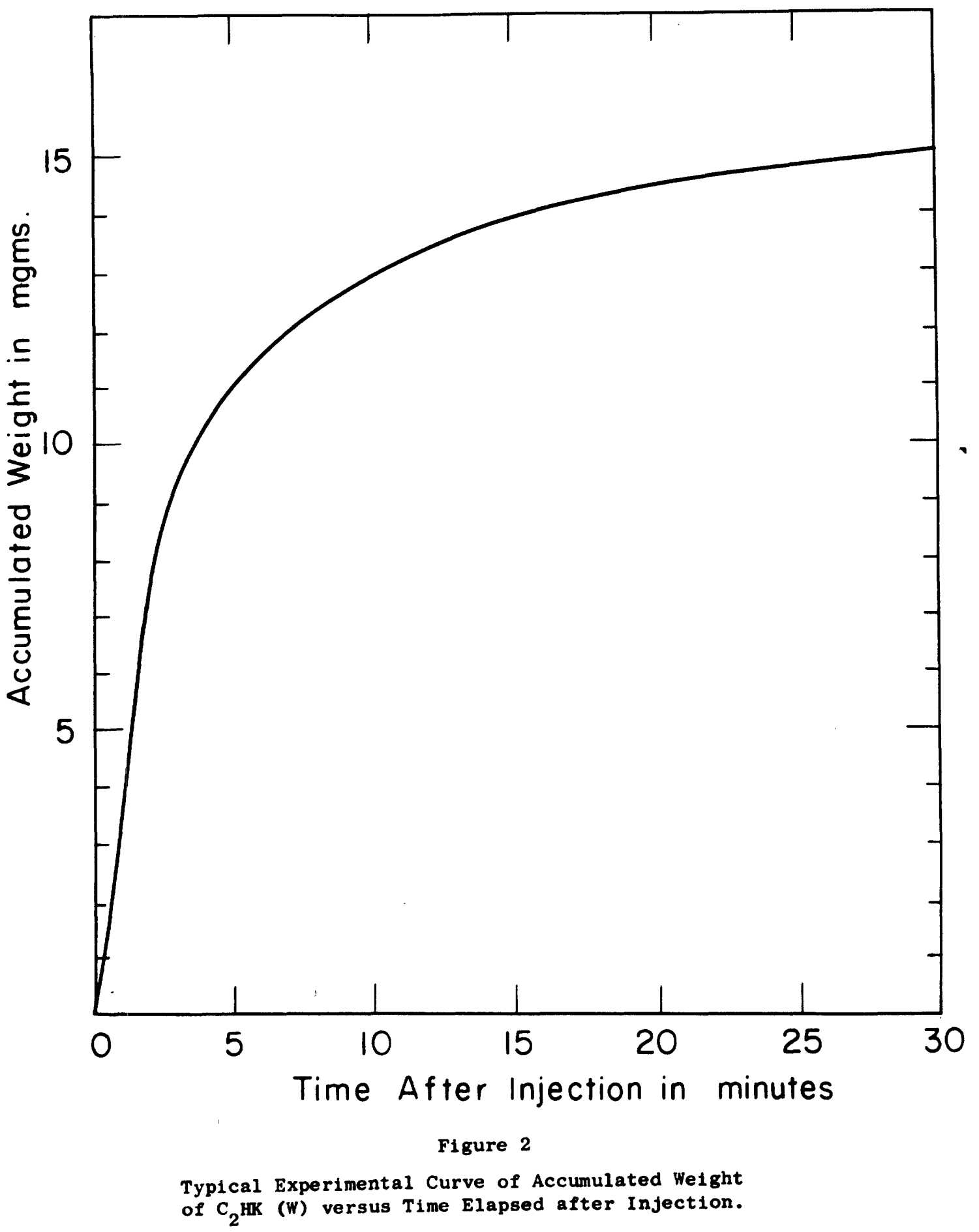




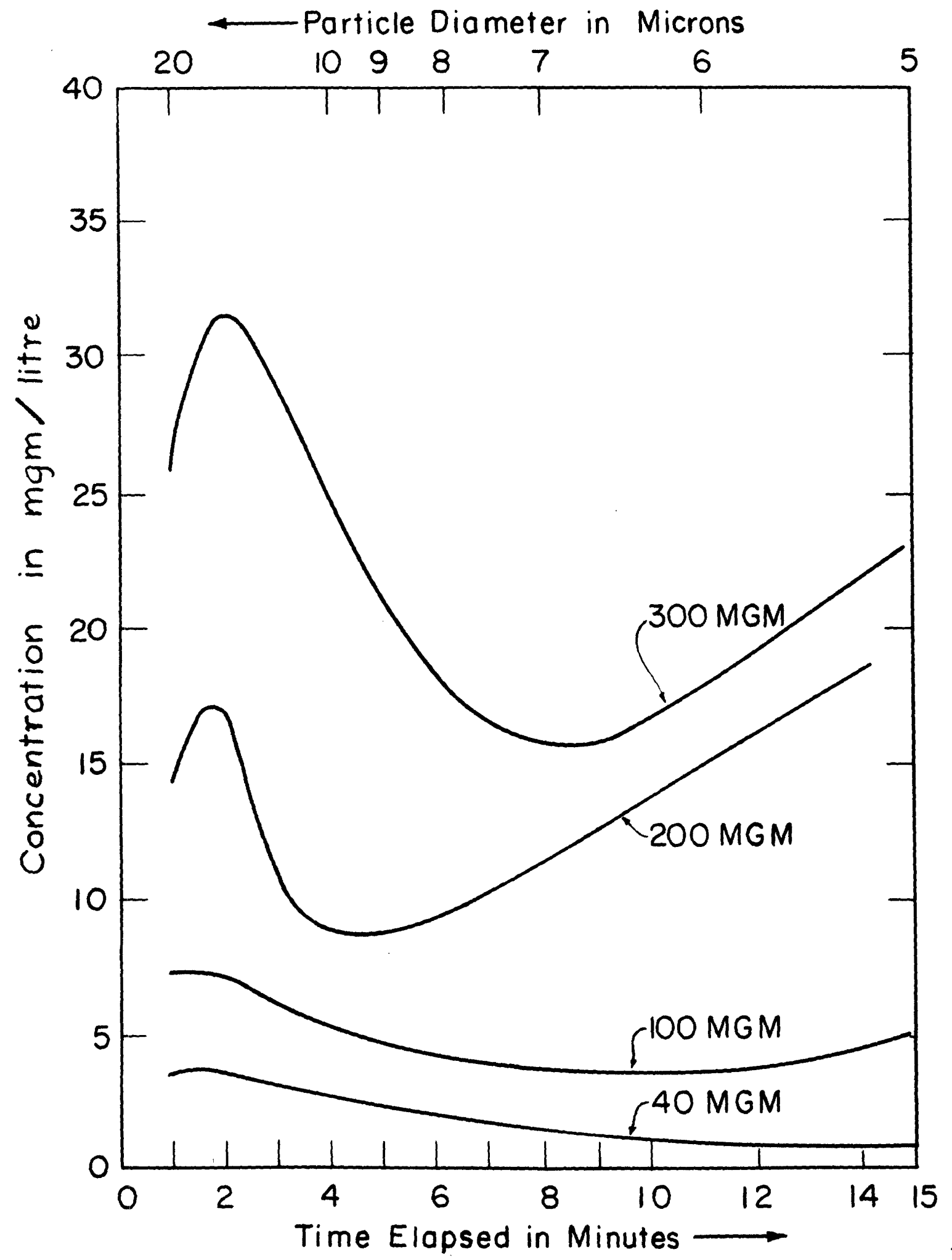

Figure 3

Concentration of Powder at Test Section as a Function of Time Elapsed after Injection for Different Amounts of Injected Powder. 


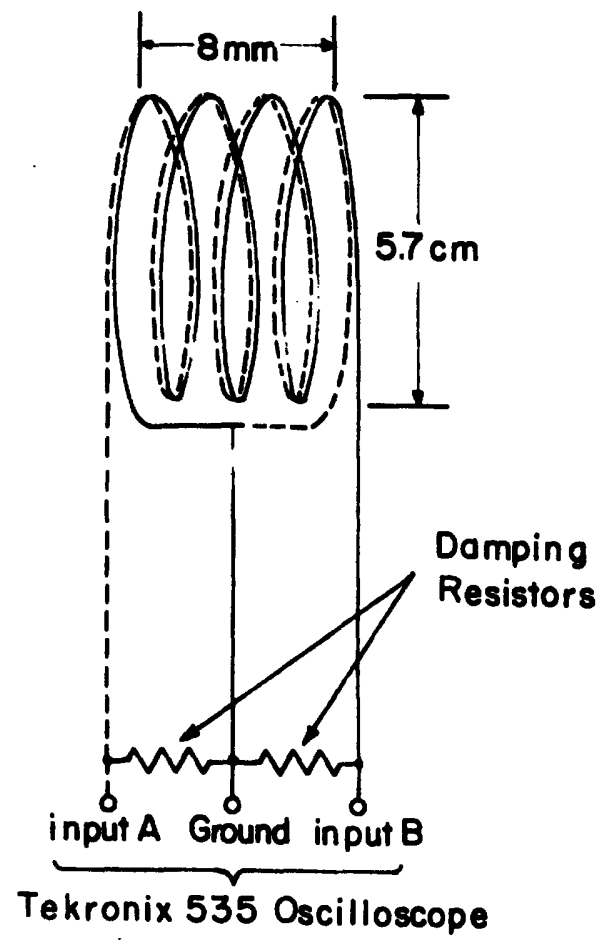

F1 gure 4

Schematic Diagram of Search Coll Used to Measure Electrical Conductivity 


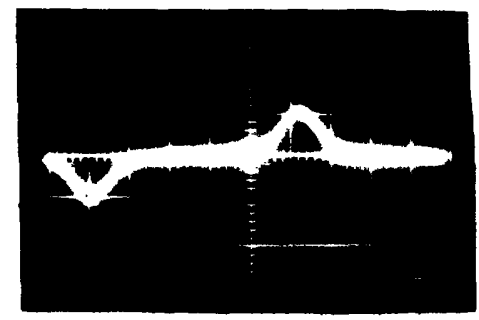

Figure 5. Calibration oscillogram obtained with the apparatus by passing an aluminium slug through the detonation tube at $600 \mathrm{~cm} / \mathrm{sec}$. The oscillogram gives the response of the apparatus to positive and negative conductivity step functions. Time runs right to left, at $5 \mathrm{milli-}$ seconds per $\mathrm{cm}$. Vertical scale is $50 \mathrm{millivolts} / \mathrm{cm}$.

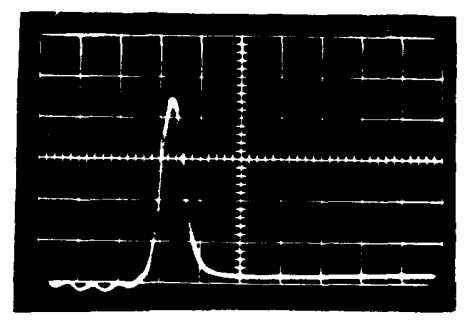

(a)

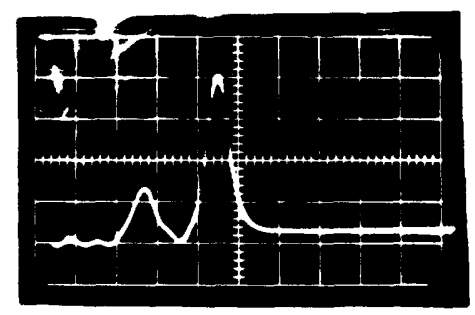

(b)

Figure 6. Typical oscillograms obtained with the apparatus when seeded detonation waves passed through the magnetic field.

(a) Single step change in conductivity.

(b) Double step change in conductivity.

Vertical Scale $10 \mathrm{mV} / \mathrm{cm}$; Horizontal Scale $20 \mathrm{microseconds} / \mathrm{cm}$. 

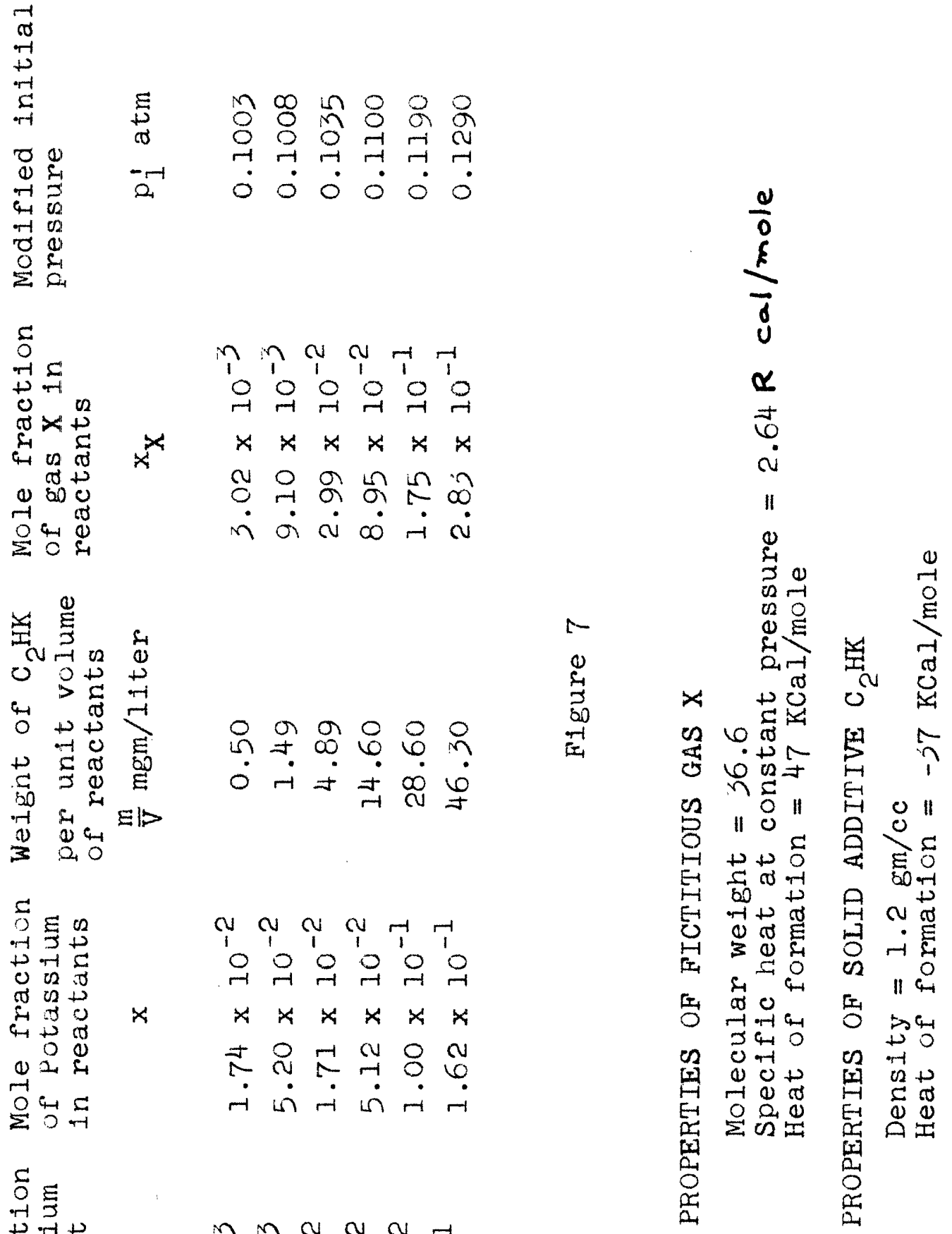

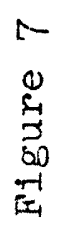

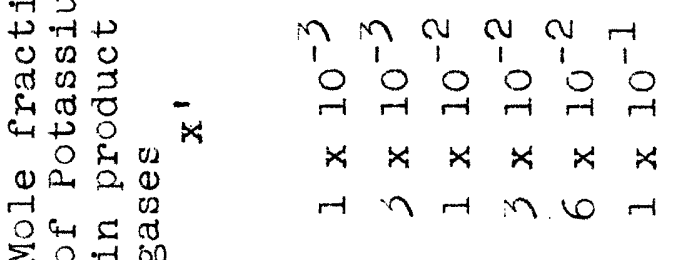




$\begin{array}{lcccc}\begin{array}{l}\text { Mole fraction } \\ \text { of Potassium } \\ \text { in product } \\ \text { gases }\end{array} & \begin{array}{c}\text { Initial } \\ \text { pressure }\end{array} & \begin{array}{c}\text { Final } \\ \text { temperature }\end{array} & \begin{array}{l}\text { Final } \\ \text { pressure }\end{array} & \begin{array}{c}\text { Gas Velocity } \\ \mathrm{u}\end{array} \\ \quad \times 1 & \mathrm{~atm} & { }_{\mathrm{K}} & \mathrm{atm} & \mathrm{cm} / \mathrm{sec} \\ 1 \times 10^{-3} & 0.1003 & 3946 & 4.190 & 1.2555 \times 10^{5} \\ 3 \times 10^{-3} & 0.1008 & 3936 & 4.193 & 1.2497 \times 10^{5} \\ 1 \times 10^{-2} & 0.1035 & 3904 & 4.211 & 1.2313 \times 10^{5} \\ 3 \times 10^{-2} & 0.1100 & 3800 & 4.176 & 1.1795 \times 10^{5} \\ 6 \times 10^{-2} & 0.1190 & 3619 & 4.042 & 1.1012 \times 10^{5} \\ 1 \times 10^{-1} & 0.1290 & 3295 & 3.652 & 9.8444 \times 10^{4}\end{array}$

Figure 8

Gas properties behind 50-50 oxy-acetylene detonation waves at initial temperature $298.16^{\circ} \mathrm{K}$. 


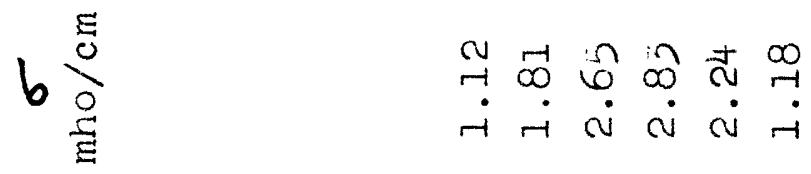

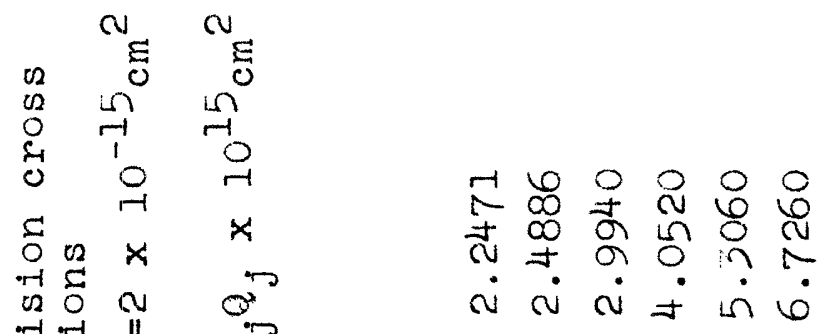

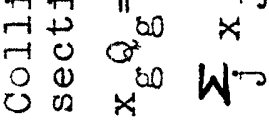

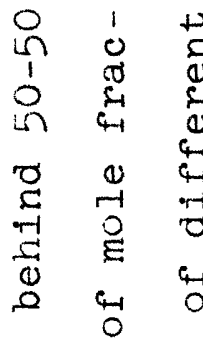

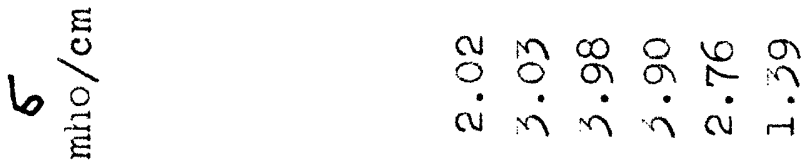

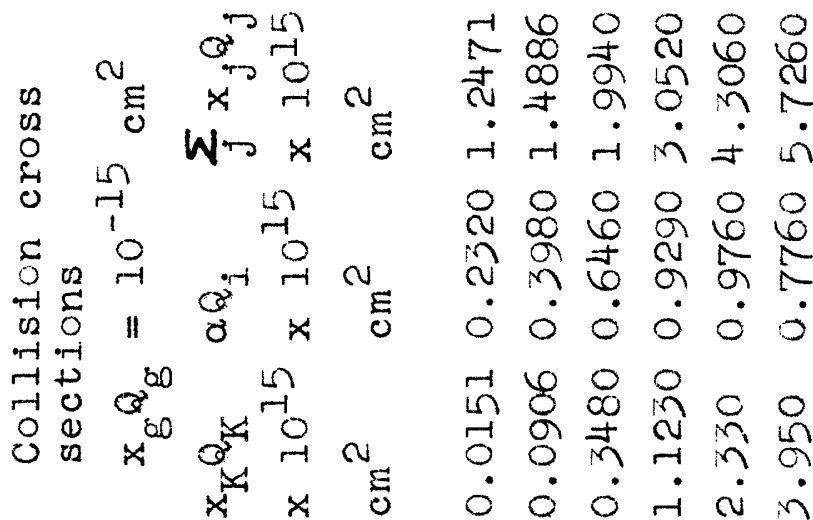

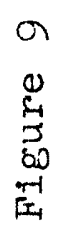

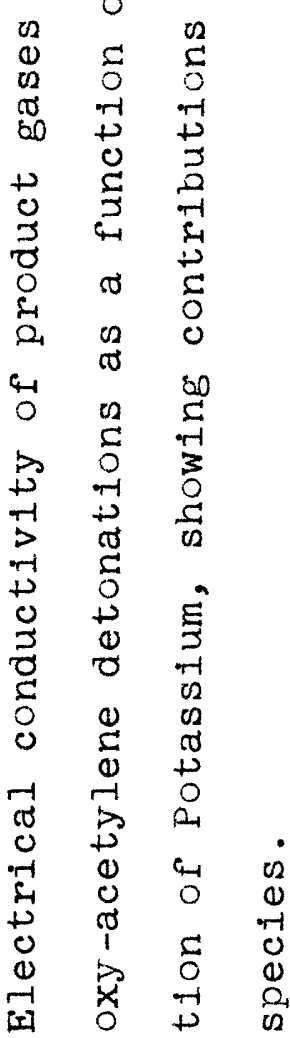

¿

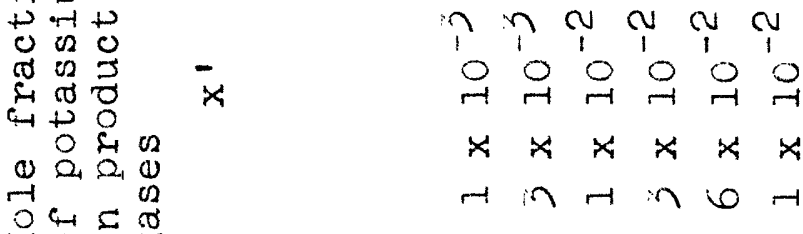

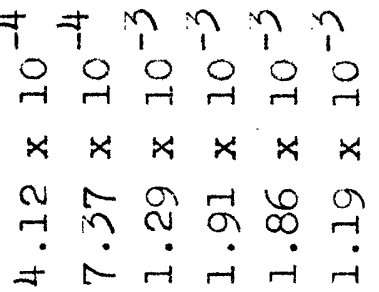




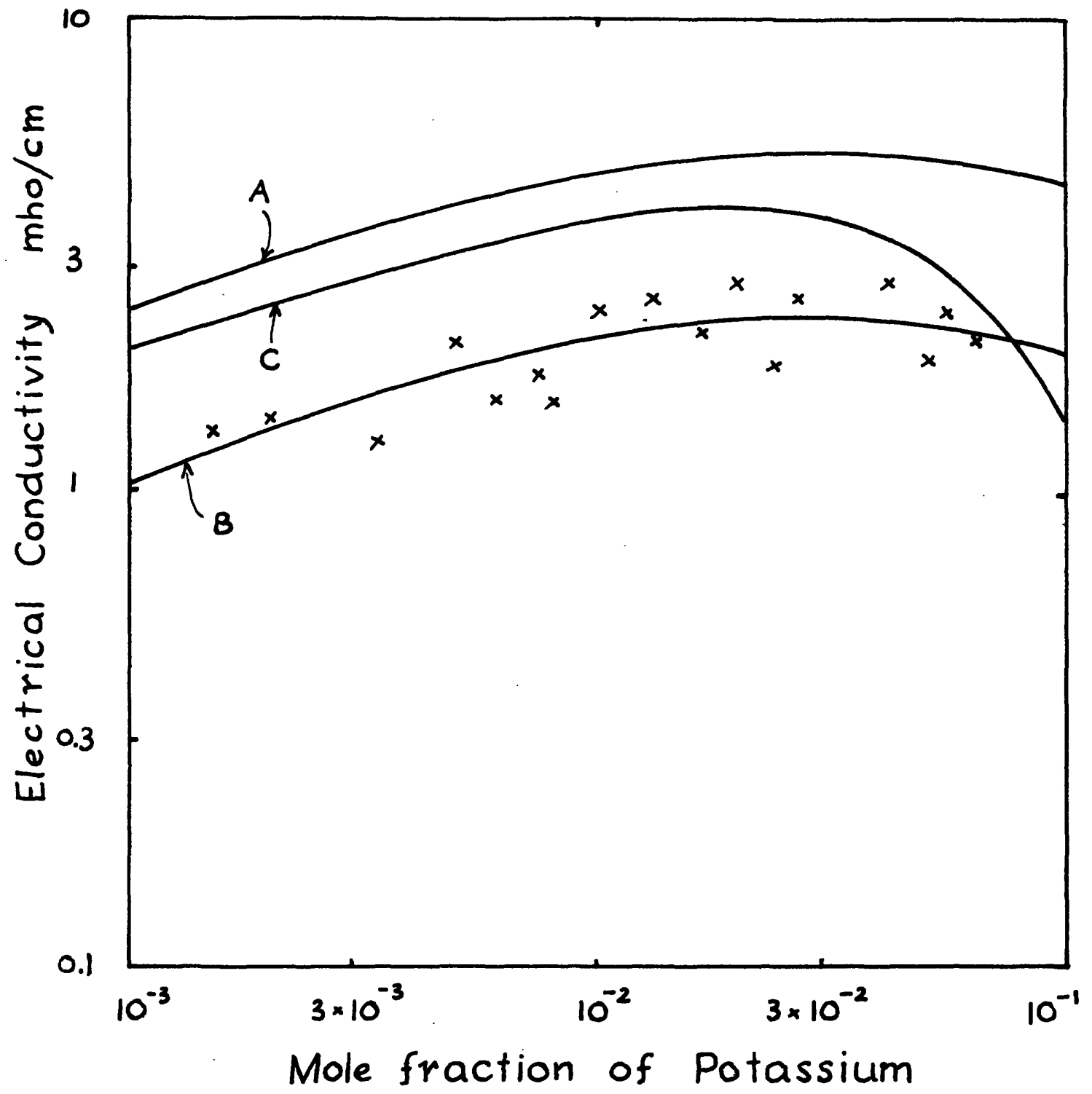

Figure 10. Comparison between experimental and theoretical electrical conductivity as a function of mole fraction of Potassium in product gases. Curves $A$ and $B$ are constant temperature lines corresponding to $4000{ }^{\mathrm{K}}$ and $3500 \% \mathrm{~K}$ respectively. Curve $C$ corresponds to experimental conditions with $Q_{g}=10^{-15} \mathrm{sq} . \mathrm{cm}$. and $Q_{K}=4 \times 10^{-14} \mathrm{sq} \cdot \mathrm{cm}$. $x$ denotes an experimental point. 


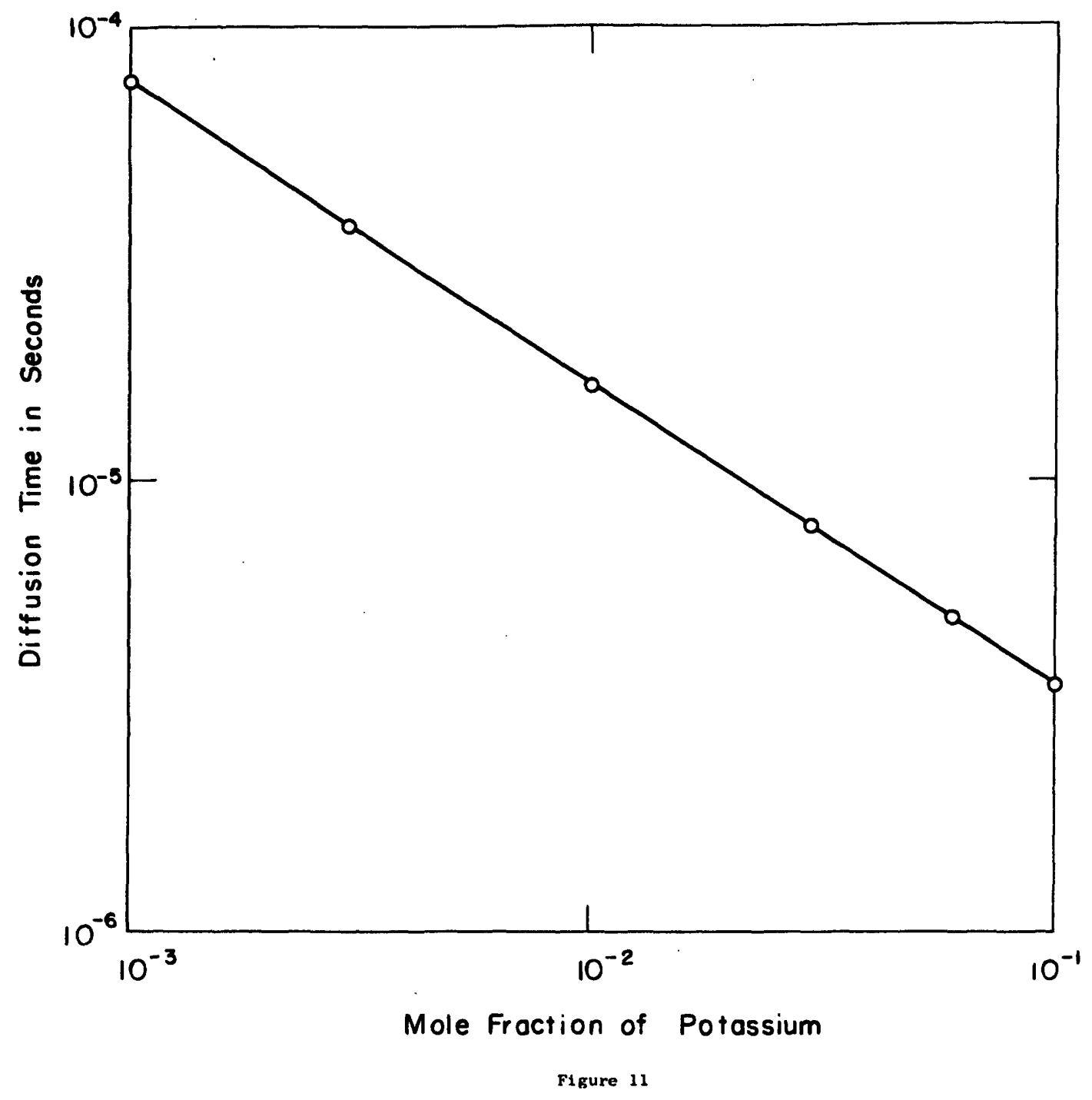

Diffusion time of Potassium in the product gases

as a function of mole fraction of Potassium for 10 micron diameter particles, assuming a diffusion cross section of $3 \times 10^{-16} \mathrm{sq} \mathrm{cm}$. 


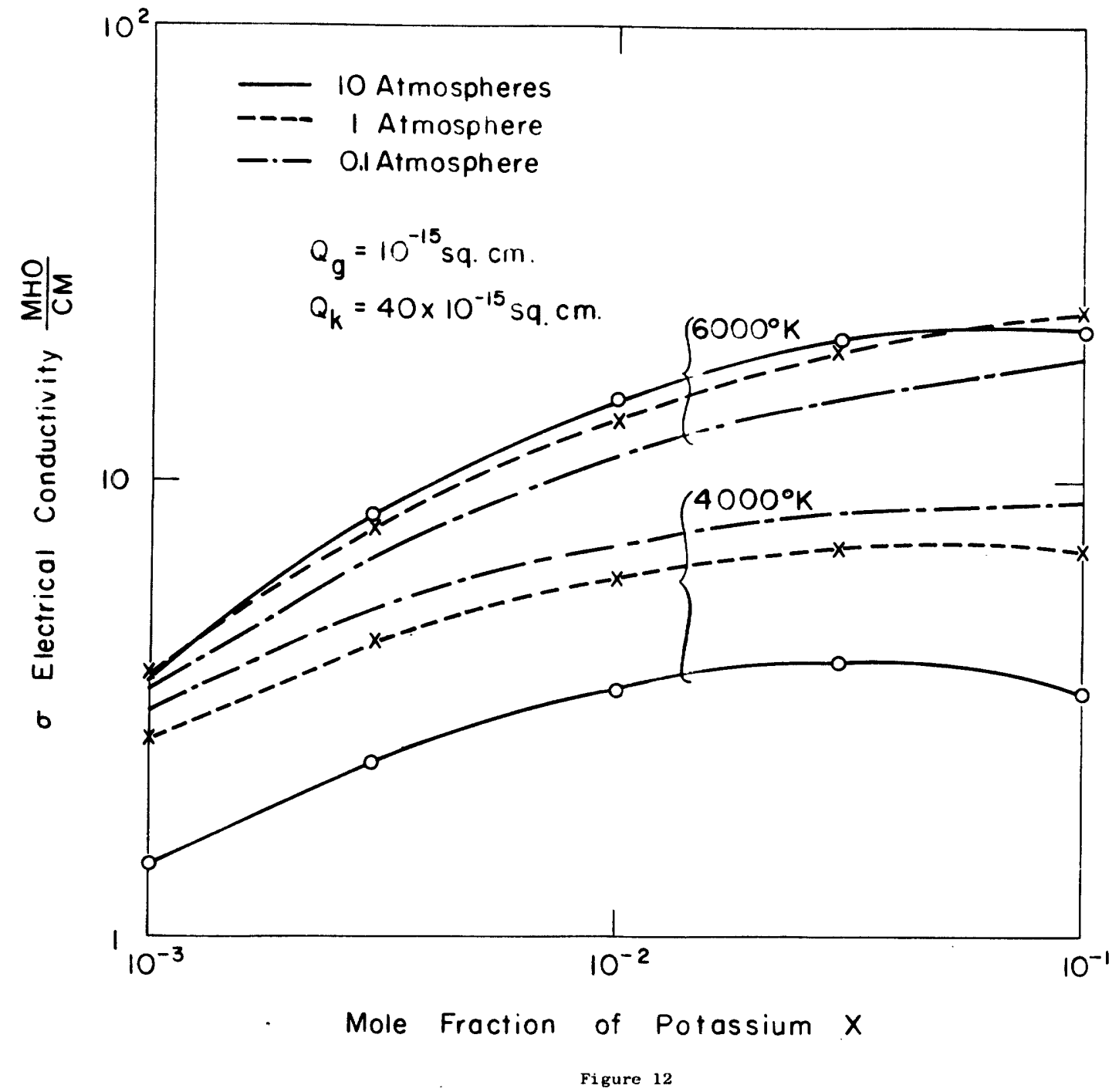

Theoretical electrical conductivity as a function of mole fraction of Potassium for three pressures $1 / 10 \mathrm{~atm}$, $1 \mathrm{~atm}$ and $10 \mathrm{~atm}$ and two temperntures $4,000^{\circ} \mathrm{K}$ and $6000^{\circ} \mathrm{K}$. $Q_{\mathrm{B}}=10^{-15} \mathrm{sq} \mathrm{cm}$. 
64.

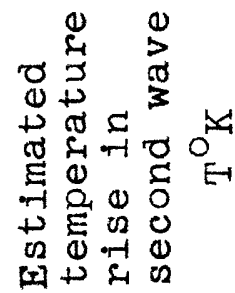

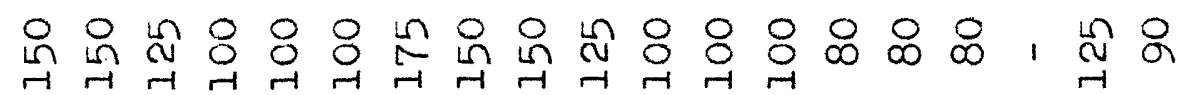

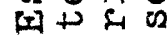

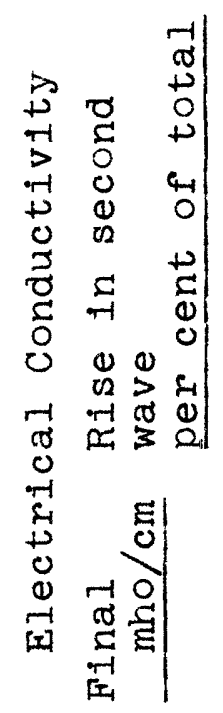

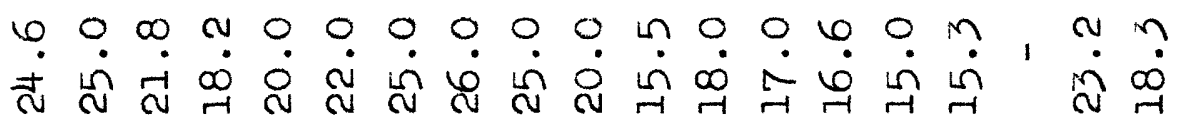

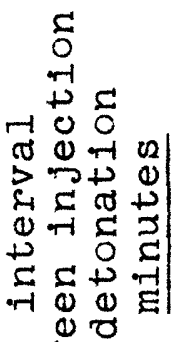

I

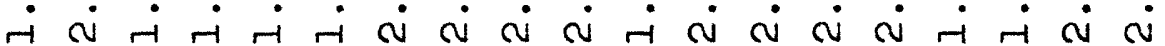

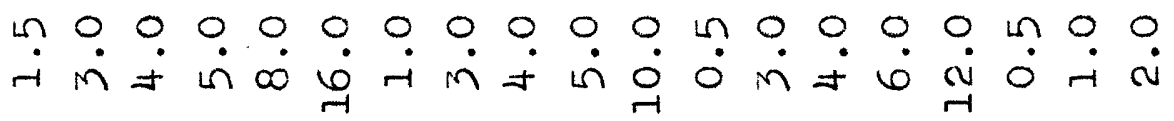

03

兵通造

Ei \&

1
0
0
3
0
0
2

H.

$\underset{-1}{8}$

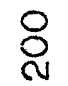

@

$+\stackrel{+}{0}$

5

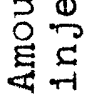




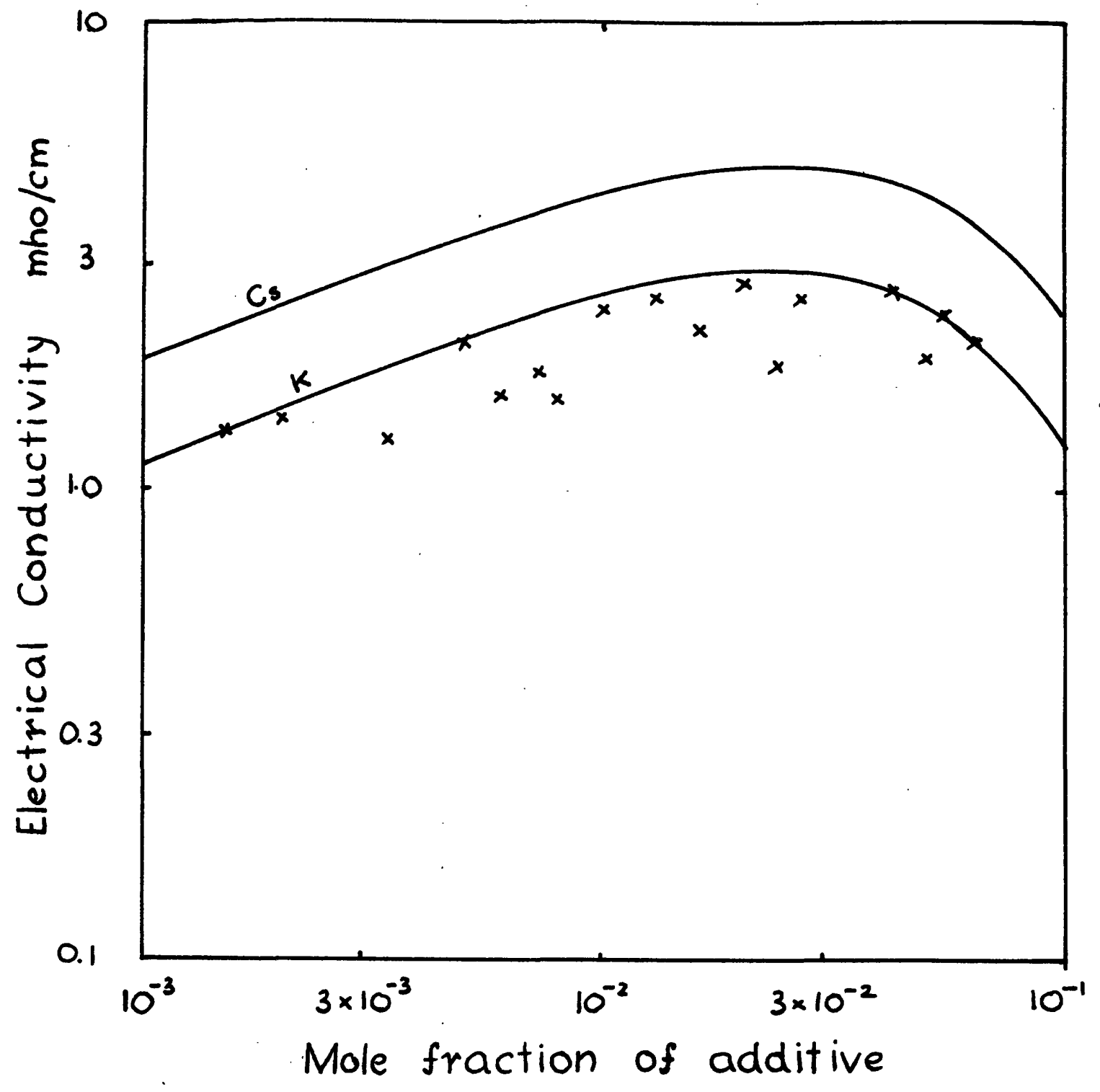

Figure 14. Comparison between experimental and theoretical electrical conductivity as a function of mole fraction of additive. Curve $K$ corresponds to Potassiun with

$$
Q_{\mathrm{g}}=2 \times 10^{-15} \mathrm{sq} \text {. cm. and } Q_{\mathrm{K}}=4 \times 10^{-14} \mathrm{sq} \cdot \mathrm{cm} \text {. }
$$

$X$ denotes an experimental point. Curve Cs corresponds to Cesium with

$$
Q_{g}=2 \times 10^{-15} \mathrm{sq} \cdot \mathrm{cm} \text {. and } Q_{C s}=4 \times 10^{-14} \mathrm{sq} \cdot \mathrm{cm} \text {. }
$$

